\title{
Visible Light Communication System Based on Software Defined Radio: Performance Study of Intelligent Transportation and Indoor Applications
}

\author{
Radek Martinek *,+(D), Lukas Danys *,+(i) and and Rene Jaros *,+(i) \\ Department of Cybernetics and Biomedical Engineering, Faculty of Electrical Engineering and Computer \\ Science, VSB-Technical University of Ostrava, 17. listopadu 15, 70833 Ostrava, Czech Republic \\ * Correspondence: radek.martinek@vsb.cz (R.M.); lukas.danys@vsb.cz (L.D.); rene.jaros@vsb.cz (R.J.); \\ Tel.: +420-721-009-971 (R.M.); +420-734-239-361 (L.D.); +420-774-650-522 (R.J.) \\ + These authors contributed equally to this work.
}

Received: 28 February 2019; Accepted: 10 April 2019; Published: 15 April 2019

\begin{abstract}
In this paper, our first attempt at visible light communication system, based on software defined radio (SDR) and implemented in LabVIEW is introduced. This paper mainly focuses on two most commonly used types of LED lights, ceiling lights and LED car lamps/tail-lights. The primary focus of this study is to determine the basic parameters of real implementation of visible light communication (VLC) system, such as transmit speed, communication errors (bit-error ratio, error vector magnitude, energy per bit to noise power spectral density ratio) and highest reachable distance. This work focuses on testing various multistate quadrature amplitude modulation (M-QAM). We have used Skoda Octavia III tail-light and Phillips indoor ceiling light as transmitters and SI PIN Thorlabs photodetector as receiver. Testing method for each light was different. When testing ceiling light, we have focused on reachable distance for each M-QAM variant. On the other side, Octavia tail-light was tested in variable nature conditions (such as thermal turbulence, rain, fog) simulated in special testing box. This work will present our solution, measured parameters and possible weak spots, which will be adjusted in the future.
\end{abstract}

Keywords: multistate quadrature amplitude modulation (M-QAM); visible light communication (VLC); software defined radio (SDR); sofware defined optics (SDO); LED tail-light; LED indoor ceiling light; vehicle-to-everything (V2X); nature conditions (thermal turbulence, rain, fog); bit-error ratio (BER)

\section{Introduction}

In recent years, visible light communication (VLC) surfaced as an alternative to classical radio frequency (RF) technology [1-3]. Current communication bands often lack free channels, which is notable particularly in Wi-Fi or in industrial, scientific and medical bands. VLC is an optical wireless standard which operates from 380 to $780 \mathrm{~nm}$, using a visible light source as a signal transmitter, free space environment as transmission medium and the appropriate photodiode/photodetector as a receiver. VLC seems to be capable technology for short-range or possibly in the future even long-range communications. Future appliances vary greatly, spanning from vehicle-to-vehicle [4-9] communications, infrastructure-to-vehicle communications or simply as an alternative to typical local area networks (LAN) [10,11].

A number of papers focused on multiple VLC technologies [12]. Light-fidelity (Li-Fi) [13-20] is slowly surfacing as commercially available alternative to Wi-Fi [21]. Orthogonal frequency division multiplexing in car-to-car was tested in real-world driving scenarios by Shen et al. [22]. 
VLC on software defined radio (SDR) $[23,24]$ is evolving quickly. In 2011, a 1 Mbps video stream was achievable over 3 meters, when deployed on custom LED matrixes [25]. In 2015, Hussain et al. tested the implementation of IEEE 802.15.7, they achieved results according to this standard, however transmission distance was limited to $1 \mathrm{~m}$ [26]. Nowadays, we are testing longer distances and mainly higher data rates, even on commercial light sources.

Rapid expansion of LED is crucial for this technology, as it offers multiple advantages such as long lifespan, low power consumption, high tolerance to humidity, high efficiency, and fast switching. However the main advantage of VLC based on LED is the use of the visible spectrum (380-780 nm). For this reason LED can perform communication functionality while maintaining the original function as illumination lighting. In this paper, we used commercially available and currently used light sources. For this purpose, a Skoda Octavia III tail-light without any modifications was chosen. To test indoor deployment, we have also used Phillips Fortimo DLM 30044 W/840 Gen3 [27]. Avalanche photodiodes (APD) and positive-intrinsic-negative (PIN) detectors are commonly used as receivers. We used Thorlabs PDA36A-EC PIN [28] photodetector with $13 \mathrm{~mm}^{2}$ of active area as receiver, since it was the most suitable candidate from available portfolio.

Our work is aimed at implementation of a vehicle-to-everything (V2X) system with highly modular design [29-31]. For this reason, we have developed a system, based on SDR. Each individual component can be swiftly exchanged, without any necessary adjustments to original code. Concept of V2X is based on the passing of information from a vehicle to any appropriate entity and vice versa. It is also often divided into different subsections, such as vehicle-to-infrastructure (V2I) [32,33], vehicle-to-network (V2N) [34,35], vehicle-to-vehicle (V2V) [36,37], vehicle-to-pedestrian (V2P) [35,38], vehicle-to-device (V2D) [39,40] and vehicle-to-grid (V2G) [41,42], vehicle-to-home (V2H) [43,44]. To test these concepts, we have also built our own testing polygon named BroadBAND light. As Skoda cars are the most widespread vehicles in the Czech Republic, we have picked Skoda Octavia III tail-light as the transmitter in V2X scenarios. So far, the partnership with manufacturers of these lights have yielded results, as we have received multiple samples of planned or already available products for testing. Philips Fortimo DLM300 is the most deployed LED indoor ceiling light in Czech Republic, so we used it in indoor experiments. Most Czech public institutions deploy exactly this type-testing it is the most logical step, as we can use every ceiling light at our university as transmitters.

Figure 1 describes different ways of V2X communication [30,45,46], mentioned earlier. V2V is a system, which enables car to communicate with each other. Its main goal is to reduce vehicle collisions and crashes. It will be a backbone of multiple levels of autonomy, delivering assisted driver services like collision warnings [32,47,48]. One key issue with V2V is that to be most effective, it should reside in all cars on the road. However, this technology has to start somewhere, so car manufacturers are slowly introducing their solutions. V2D is a system, that links cars to many external receiving devices and will be particularly useful to bikers. Vehicles can communicate with V2D device on cycle to alert rider to potential danger or to avoid accidents $[39,40,49]$. V2P is a system which should be particularly useful to elderly persons, school kids and physically challenged persons. V2P maintains a link between pedestrian's smart devices and vehicles to act as an advisory to avoid collisions [50,51]. V2H communications involve a link between a vehicle and the owner's home, sharing the task of providing energy [52,53]. During power outages, a vehicles battery can be used as a critical power source. V2G is a system which can communicate with the power grid to adjust the vehicle's charging rate [54,55]. It will be an element in some electric vehicles and is used as a power grid modulator to dynamically adjust to the energy demand [56]. 


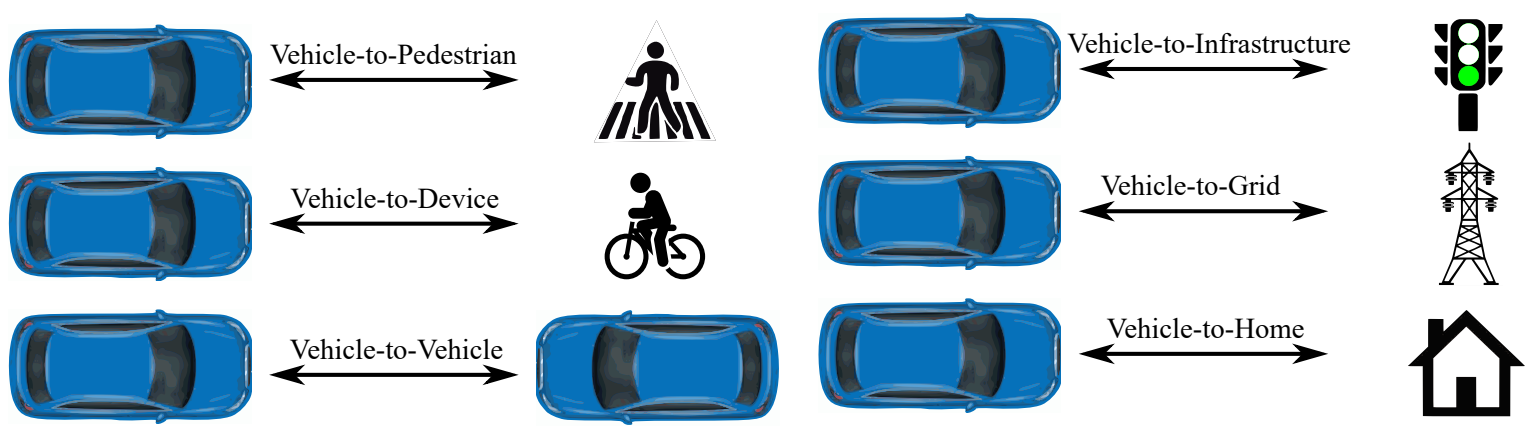

Figure 1. Vehicle-to-everything scenarios communication.

Figure 2 describes proposed different ways of indoor visible light communication (VLC) communication. Smart lighting inside smart buildings provides the infrastructure for illumination, control and communications and will greatly reduce energy consumption within a building. Smart appliances, meters or factory applications, especially in dangerous conditions are all possible target devices. Direct connection between mobile devices might be possible as well, since modern smartphones have illumination LEDs which might be used as transmitters and cameras, which could work as receivers. There are advantages of using VLC in hospitals and healthcare [57-60]. RF technologies are mostly undesirable in certain parts of hospitals, especially around MRI scanners and in operating theatres. VLC deployment in aviation is also desirable. Radio is undesirable in passenger compartments of aircrafts. Modern aircrafts already use LEDs for illumination, so VLC might replace wiring to passenger seats. This might reduce aircraft construction costs and weight [61,62].
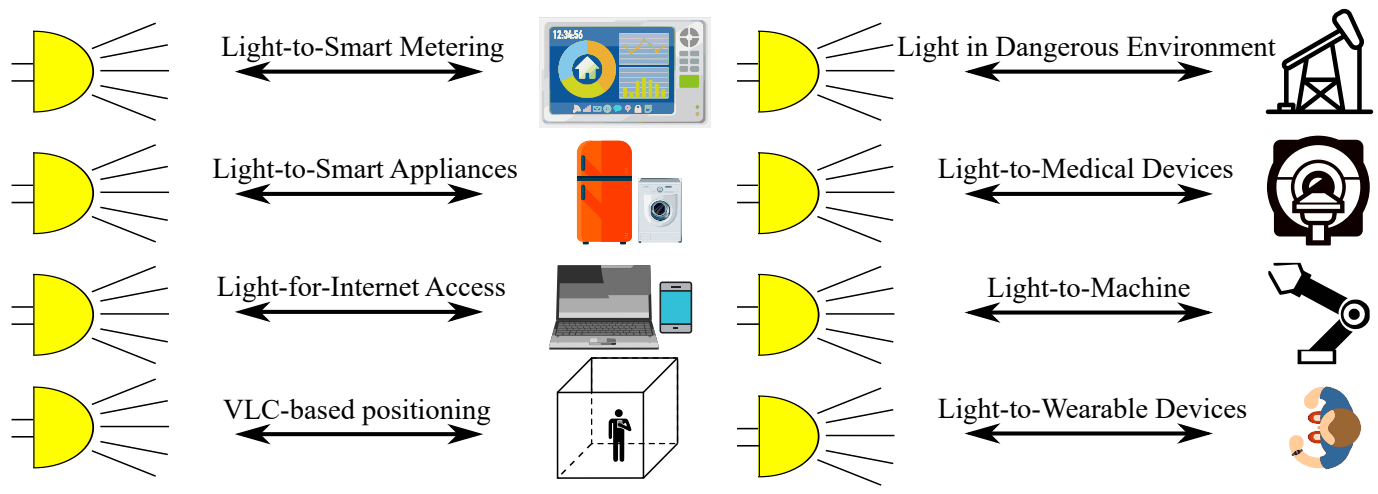

Figure 2. Indoor VLC scenarios.

Factory applications are especially interesting. There are multiple benefits to machine to machine VLC solutions (machine-to-machine communication - M2M [20,63-66]). Smart factories could be built upon enhanced industrial instrumentation, such as advanced sensors or meters. VLC can be also used to coordinate the movement and timing of robots in manufacturing settings, such as automobile factories. It can provide location-based communications to automated guided carts and "smart cart" robots or provide drone-to-station communications for precise, interference-free movement, drop zones and landing sites $[67,68]$.

Vehicular visible light communication (V-VLC) $[46,69-73]$ is often described as supplementary or "sister" technology to planned 5G [31]. There is also a concept of social internet of vehicles (SIOV) [74-76], which is based on LTE/4G network, consisted of multiple road side units (RSU) based on eNodeB base stations and on-board units (OBU) with LTE/4G capabilities. SIOV consists of multiple entities, which are treated as nodes connected to each other via links. However this concept can be further expanded by VLC implementation. Daytime running lamps (DRL) are often mandatory in European countries and optional VLC capabilities would possibly save energy needed to maintain continual 4G/5G connection $[77,78]$. 
Multiple teams implemented VLC using SDR and LabVIEW, with different success. A turkish team successfully carried out a number of experiments, using simpler on-off keying (OOK) and variable pulse position modulation (VPPM) modulations [79]. Another team from Chile managed to implement their own system using similar hardware [7]. However, there are two main concerns. Both teams do not mention their maximal reached transmit speed and the used photodetector (PDA36A) is certainly a limiting factor, as we have run a number of tests on it as well. According to manufacturer's datasheet, increasing gain of its trans-impedance amplifier significantly limits useable bandwidth. According to the state of art study, universal software radio peripherals(USRPs) are more than capable of being used in VLC experiments [80]. They also mention the necessary adjustments and possible limitations of lower end (USRP 292X) models. That's why we switched to much more powerful and newer models which will be used in future experiments [7,79-82].

As mentioned before, the described system is our team's first attempt at SDR VLC quadrature amplitude modulation(QAM) system. Different teams have already delved into different problematics, such as adaptive modulation schemes [83]. Multiple input multiple output design described by Deng et al. 2017 [84] is already implementing higher state QAM modulation schemes capable of adaptive switching. Designing similar systems based on orthogonal frequency division multiplexing (OFDM) will be a topic of imminent research, as we are already switching to more capable hardware components $[85,86]$. Khalid et al. investigated the implementation of a VLC system based on DAQ hardware [87]. This system is however very limited performance-wise. The second iteration of our prototype will be also based on LabVIEW, but we are focusing on field programmable gate array (FPGA) implementation, as it will increase performance dramatically.

There are multiple advantages to practical implementation of VLC. Each of presented solution has its own use and advantages. When approaching the problems of V2V communication, the natural conditions are major concerning factor, as they significantly vary throughout the year. Carrying out a number of experiments in this area is a logical first step in implementation of channel equalization, as we estimate it will significantly improve transmit speeds or reachable distance. Also we tested our modular platform in previously mentioned conditions, as it will become a basic platform, which will be modified and improved in the future. Currently, we are exploring outdoor car lamps, tail-lights, and indoor ceiling lights, as these light sources that are the most perspective. In the future we will also include street lamps, as V2I and V2V outdoor experiments will be carried out in previously mentioned testing polygon, which is already running on LEDs, so every lamp is prepared for VLC.

Tsiropoulou et al. [88] have investigated problematics of non-orthogonal multiple acces (NOMA) vs. orthogonal frequency division multiple access (OFDMA) approach [89-91]. According to her, NOMA offers us multiple advantages, such as considerable interference mitigation or simultaneous bandwidth utilization. Also due to the absence of resource block per user, NOMA can sufficiently accommodate more users than OFDMA. Modern mobile networks based on LTE use the OFDMA approach, as it is a basis of LTE standardization. Car manufacturers are currently enrolling LTE modules into vehicles and are preparing for 5G transfer. Currently, 5G is surfacing technology, which was deployed in only a limited number of countries. However $5 \mathrm{G}$ is based on NOMA, so its implementation in VLC is necessary if both technologies should coexist or work in conjunction. Lin et al. also tested hybrid NOMA/OFDMA approach with partial success [92].

Tsiropoulou et al. [93] propose a concept of visible light communication local area networks (VLC-LANs), where users are served by optical access points (OAPs). In this scenario, VLC-LANs [94] are presented as alternative to macrocell area coverage. Two-tier VLC topology is considered, mostly for indoor and outdoor coverage. The system is based on OFDMA, basically to be ready for LTE incorporation. Each user communicates directly with a single OAP via communication link. OAPs total bandwidth is divided into subcarriers, which are organized in resource block (RB). Each RB is occupied exclusively by one user. This concept could be easily adapted for 5G by introduction of NOMA, as discussed earlier. 


\section{Experimental Setup}

Experimental setup is based upon application created in LabVIEW, which was used for input/output signal processing and measurement. Application output was fed into NI USRP-2921 [95], which stands for transmitting element. Signal was then amplified by a $1.6 \mathrm{~W}$ amplifier, effectively working from 1 to $200 \mathrm{MHz}$. The amplified signal went through bias tee into the transmitting light source, which can be exchanged at will. A photodetector was located at a variable distance from the transmitting element. It was also possible to insert special measuring box, used for simulation of multiple nature conditions, such as fog, rain or thermal turbulence. Received signal was fed into NI USRP-2921 whose output is connected to the same computer running LabVIEW application. Signal was then evaluated, and parameters were displayed accordingly. This whole setup was designed with the highest possible modularity in mind. We wanted to switch each component at will and observe their direct impact on whole prototype.

We had to swap NI USRP-2921 transmitting and receiving boards with Ettus LFRX/LFTX Daughterboards, which were operating at 0-30 MHz. This band was approximately what we had in mind when designing whole prototype, as USRP capabilities were one of the biggest limiting factors. Original boards from 2921 were designed for $2.4-2.5 \mathrm{GHz}$ and $4.9-5.9 \mathrm{GHz}$, which was completely unsuitable for our needs. We had also adjusted connectors on the Octavia tail-light, as they were designed for car engine control unit. To further improve RSL when transmitting using tail-light, we had mounted a planoconvex lens on a photodetector to focus received light into the converging beam with lens focus at the active area of photodiode. However, since we measured RSL at variable receiving angle when using stationary ceiling light as source, it was undesirable to use lens in this different scenario. We have chosen ZX85-12G+ bias tee [96], which operates from $0.2 \mathrm{MHz}$ to $12 \mathrm{GHz}$, its maximal current is $0.4 \mathrm{~A}$ and maximal input voltage is $25 \mathrm{~V}$. There are multiple parameters, that can be configured in LabVIEW application, such as:

- Carrier frequency: $\max 30 \mathrm{MHz}$

- Bandwidth

- Sample width

- Number of states: max 4096-QAM

- Message symbols

- $\quad$ Used TX filter

- TX gain

- RX gain

- $\quad$ TX device IP address

- $\quad$ RX device IP address

Tests wre carried out using static modulation formats. Long term measurements were essential to specify threshold for successful modulation switching in adaptive modulation. We were aiming for a similar system, which is used in case of microwave point-to-point links, where both units are capable of quickly changing modulation scheme according to natural conditions and measured parameters. Sacrificing part of the transmission speed in favor of link robustness is the main concept of this system.

\section{Evaluation Parameters}

Received signal level (RSL), which signalize signal strength received at second, or receiver, USRP. It is the sum of all losses and gains on the receiver input.

Our LabVIEW application use channel coding with hard decision forward error correction (FEC) threshold of $3.8 \times 10^{-3}$. Data with bit-error ratio (BER) below this threshold can be repaired by FEC codes. This threshold was appropriate for our M-QAM modulation. LabVIEW Modulation Tookit [97] also includes multiple different types of channel coding [98]. The influence of these techniques on transmission quality will be a topic of further research. As FEC was not the main topic of this paper, 
we used predetermined threshold and functions already present in LabVIEW libraries. Problematics of FEC in QAM VLC was investigated by team in Edinburg [99].

Modulation error ratio (MER) [100] is defined as a relationship between error vector magnitude (EVM) and signal-to-noise ratio (SNR). It was used to quantify the performance of transmitter/receiver in the system, which used digital modulations (in this case QAM). It is influenced by various imperfections in the implementation (such as noise, phase noise, distortion, right focusing) and characteristics of signal path which cause the actual constellation point to deviate from ideal locations.

EVM [101] is a measurement of demodulator performance in the presence of impairments (Figure 3, where $\vec{v}$ is the ideal symbol vector, $\vec{w}$ is the measured symbol vector, $\vec{w}-\vec{v}$ is the magnitude error, $\Phi$ is the phase error, and $\vec{e}=\vec{w}-\vec{v}$ is the error vector). The soft symbol decisions obtained after decimating the recovered waveform at the demodulator output were compared against ideal symbol locations. The root mean square error vector magnitude and phase error were then used in determining the EVM measurement over a window of $N$ demodulated symbols. EVM was related to the modulation error ratio. There is one-to-one relationship between EVM and MER.

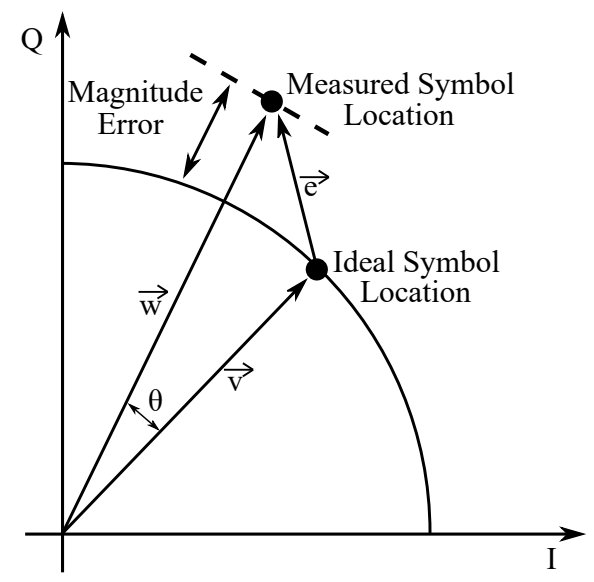

Figure 3. Error vector magnitude.

Energy per bit to noise power spectral density ratio $\left(E_{b} / N_{0}\right)$ was an important parameter in digital communications. It is a normalized SNR measure, also known as SNR per bit. It is useful when comparing BER performance of different digital modulation schemes without taking bandwidth into account. To calculate this value, SNR must be periodically obtained at receiver USRP. $\mathrm{E}_{\mathrm{b}} / \mathrm{N}_{0}$ was calculated at the receiver from the estimation of the SNR, the relationship between them is the following:

$$
\left.\frac{E_{\mathrm{b}}}{N_{0}}\right|_{\mathrm{dB}}=\left.S N R\right|_{\mathrm{dB}}+10 \log _{10}(n)-10 \log _{10}(\text { sps }),
$$

where $n$ is the amount of information bits per symbol. Both modulation order and the code rate (in case that channel coding is employed) have an influence on this value. $\mathrm{E}_{\mathrm{b}} / \mathrm{N}_{0}$ measurement on USRP is further expanded in paper by Alonso et al. [102].

\section{A Feasibility Study on Indoor Visible Light Communication}

Measurements using ceiling light were carried out under laboratory conditions (calm wind, $24^{\circ} \mathrm{C}$ ). Figure 4 describes tested setup. Our tested light source is capable to cover a conical area with radius of approximately $350 \mathrm{~cm}$, as is described on Figure 5 . We began our measurements at a right center of this covered area, directly under light source. Then, we periodically repeated measurements but moved to the edge of covered area with a step of $25 \mathrm{~cm}$. The distance between receiver and transmitter was $202 \mathrm{~cm}$. 
The following configuration was used in this scenario:

- Carrier frequency: $3 \mathrm{MHz}$

- Bandwidth: 1-4 MHz

- Modulation type: M-QAM

- TX/RX gain: $0 \mathrm{~dB}$

- Message symbols: 10,000

- Tx filter: root raised cosine

- Sample width: 16-bit

- Receiver-transmitter distance: $202 \mathrm{~cm}$

- Measured distance: 0-350 cm (step of $25 \mathrm{~cm}$ )

- Photodetector without planoconvex lens $\rightarrow$ more suitable for this scenario

- Measured parameters: $\mathrm{E}_{\mathrm{b}} / \mathrm{N}_{0}, \mathrm{BER}, \mathrm{EVM}$ and MER

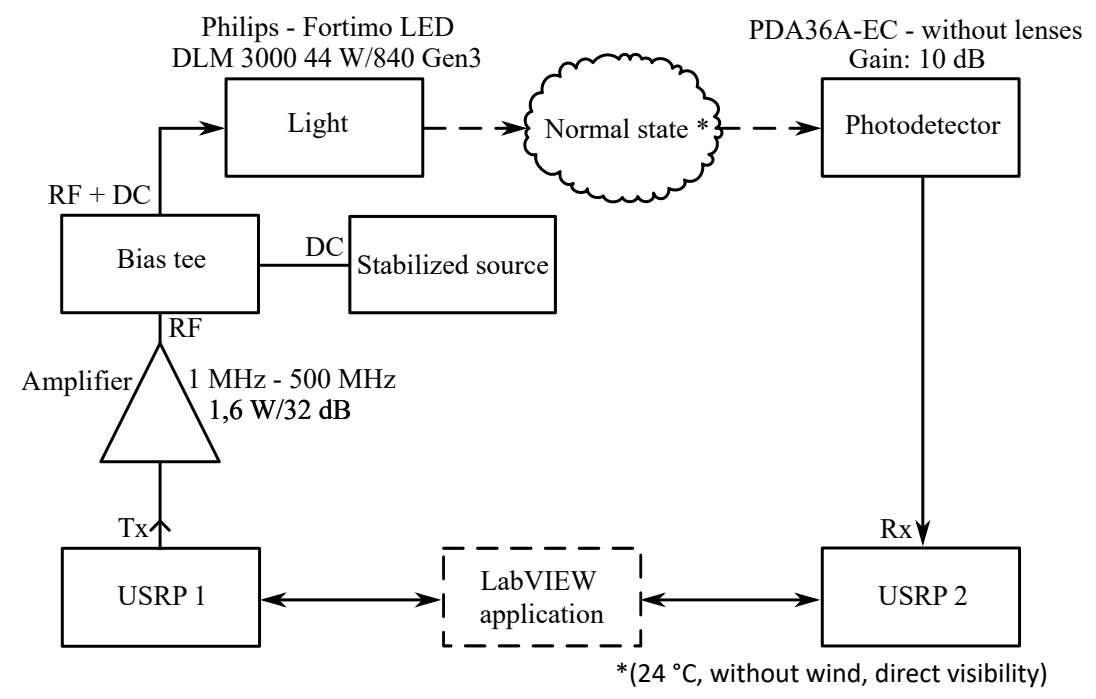

Figure 4. Ceiling light setup.

Fortimo LED DLM 300044 W/840 Gen3

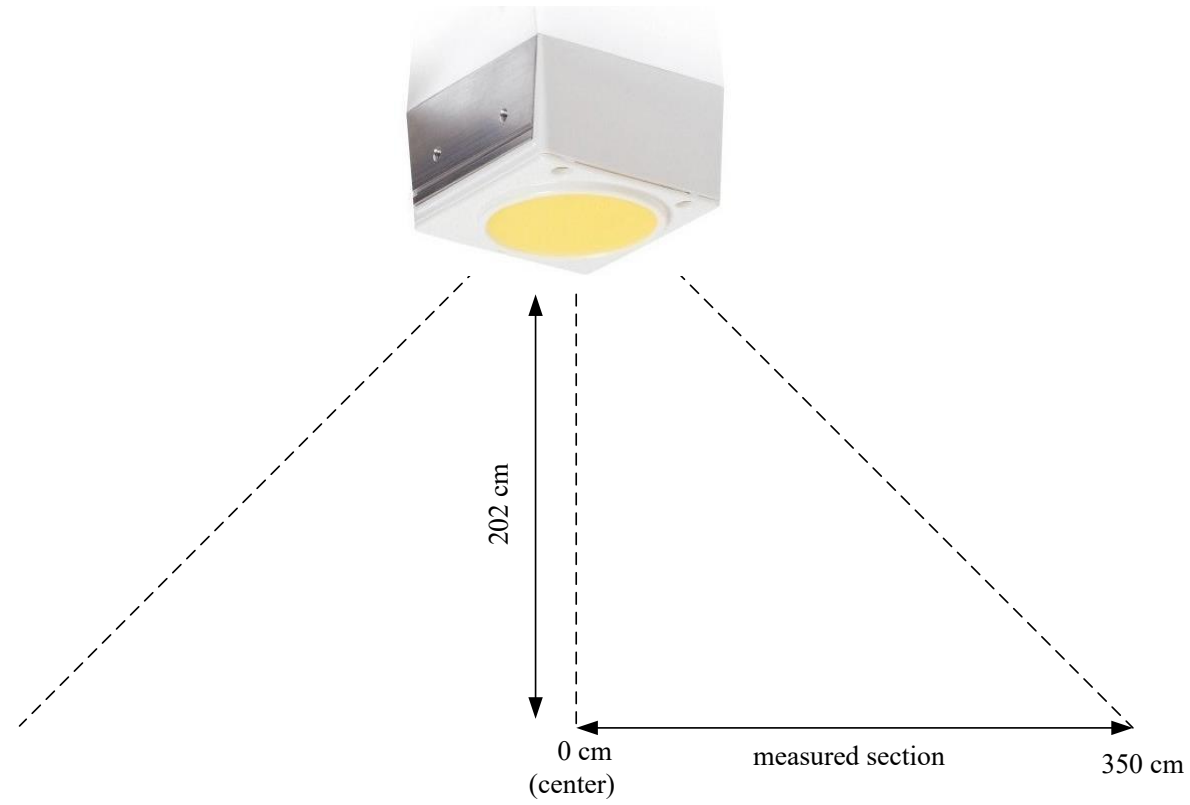

Figure 5. Setup with measured distance. 
In Table 1 you can see parameters of light of Fortimo LED DLM 300044 W/840 Gen3 and in Table 2 you can see chosen parameters of photodetector PDA36A-EC.

Table 1. Parameters of light of Fortimo LED DLM 300044 W/840 Gen3.

\begin{tabular}{cc}
\hline Initial lumens & $3000 \mathrm{~lm}$ \\
Color rendering index & 80 \\
Correlated color temperature & $4000 \mathrm{~K}$ \\
System input power & $46.0 \mathrm{~W}$ \\
System efficiency & $68.0 \mathrm{Lm} / \mathrm{W}$ \\
Input voltage & $220-240 \mathrm{~V}$ \\
Max. vitality & $5000 \mathrm{~h}$ \\
$\mathrm{U}_{\max }$ dc & $80 \mathrm{~V}$ \\
Max operating temperature & $65^{\circ} \mathrm{C}$ \\
$\mathrm{P}_{\max }$ & $40 \mathrm{~W}$ \\
\hline
\end{tabular}

Table 2. Chosen parameters of photodetector PDA36A-EC.

\begin{tabular}{cc}
\hline Type of detector & Si PIN \\
Active area & $3.6 \times 3.6 \mathrm{~mm}\left(13 \mathrm{~mm}^{2}\right)$ \\
Wavelength range & $350-1100 \mathrm{~nm}$ \\
Gain adjustment range & $70 \mathrm{~dB}$ \\
Gain step & $8 \times 10 \mathrm{~dB}$ \\
Operating temperature & $0-40{ }^{\circ} \mathrm{C}$ \\
Max output current & $100 \mathrm{~mA}$ \\
\hline
\end{tabular}

Before proceeding with the main part, we measured attenuation characteristics of our prototype by using the vector network analyzer. Figure 6 represents measured data. It is visible that attenuation quickly increased with longer distances. Even the sample with the best conditions (directly under light source) showed an increase in attenuation by $47 \mathrm{~dB}$ relative to the reference of $0 \mathrm{~dB}$. By increasing distance to $3 \mathrm{~m}$, attenuation reached $68 \mathrm{~dB}$, which negatively impacted prototype capabilities, mainly the constellation decoding. We have chosen carrier frequency of $3 \mathrm{MHz}$, so that we can increase bandwidth up to $4 \mathrm{MHz}$ without getting into sub $1 \mathrm{MHz}$ band. However, increasing bandwidth also increases the difference in attenuation between highest and lowest frequency. This fact negatively impacted constellation decoding as well. The resulting theoretical transmit speed was influenced by many factors, such as modulation scheme, used bandwidth and mainly by the distance of photodetector from center of measurements, which affected attenuation. We were able to reach $2 \mathrm{Mbps}$ at $325 \mathrm{~cm}$, by using 4-QAM with bandwidth of $1 \mathrm{MHz}$. The highest achieved transmit speed was $20 \mathrm{Mbps}$ (32-QAM, $4 \mathrm{MHz}$ ), which could be maintained up to $90 \mathrm{~cm}$ from the center. Figure 7 represent possible maximal reachable transmission speeds for different M-QAM and bandwidths. Further implementation of adaptive modulation seems like a good way to further push this prototype forward. By defining strict rules for modulation switching, we could seamlessly maintain the highest possible transmit speed while having reliable connection. For our testing, we have used BER $=10^{-5}$ as a threshold value.

The valubble in Figure 7 are theoretically achievable transmit speeds. They were calculated in LabVIEW software, but a number of measurements were carried out to verify them. Effective transmit speed varied a bit (by approximately hundreds of kbps), because it was practically impossible to design an ideal channel. However deviations were so small, it was possible to neglect them. 


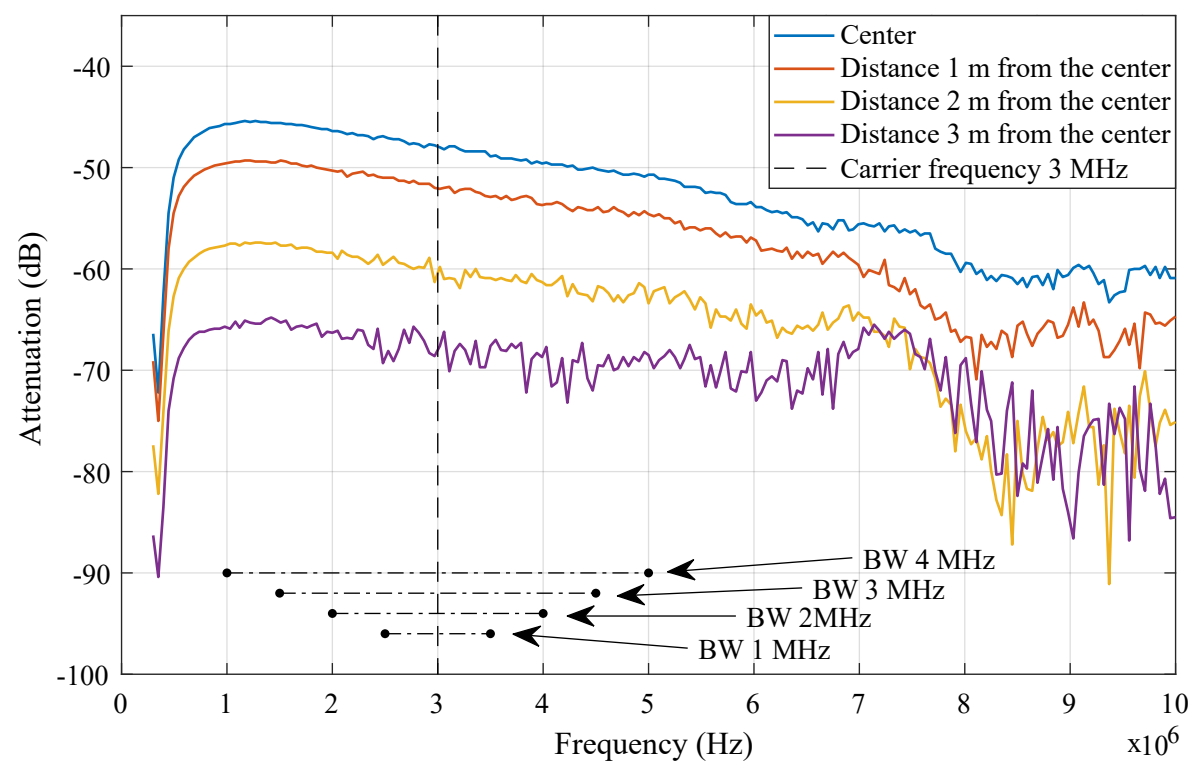

Figure 6. Attenuation characteristics of ceiling setup.

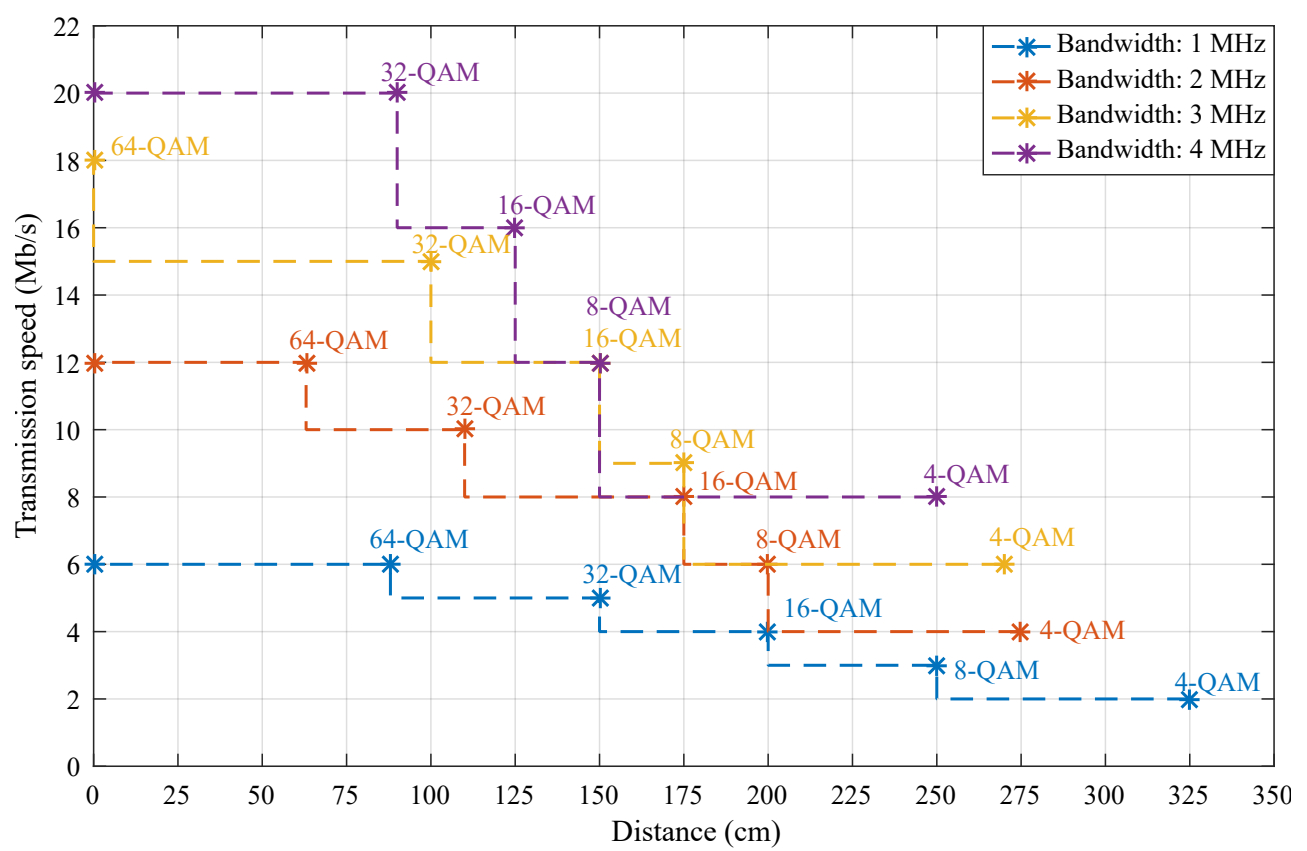

Figure 7. Transmit speed/distance from center relationship for ceiling light with different M-QAM and bandwidths.

Figure 8 represents a constellation diagrams of 4-QAM modulation measured at different distances and channel widths. It is noticeable that constellation points of the $4 \mathrm{MHz}$ channel width measurements were more spread from their ideal position. These diagrams did not exceed the BER threshold mentioned earlier, but implementation of higher state modulation at limiting distance would result in rapid increase of BER and might even end in complete link degradation. 
RX Constellation

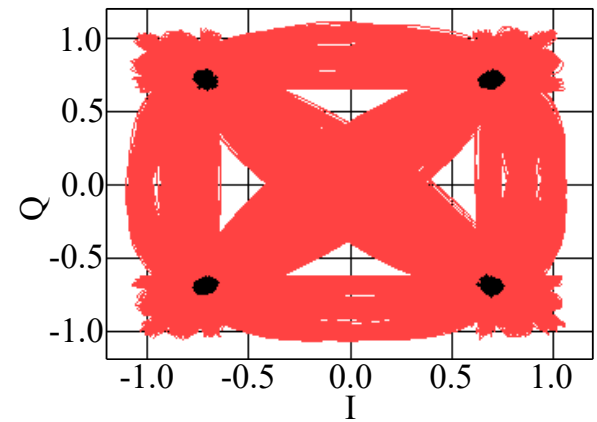

(a)

RX Constellation

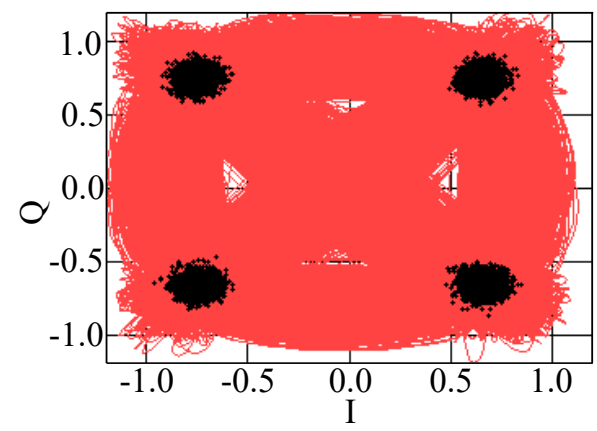

(c)
RX Constellation

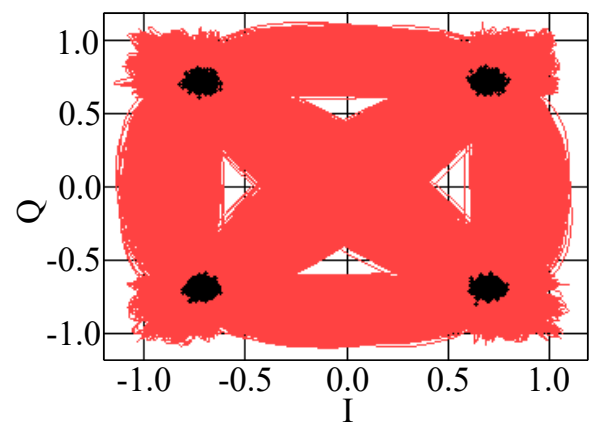

(b)

RX Constellation

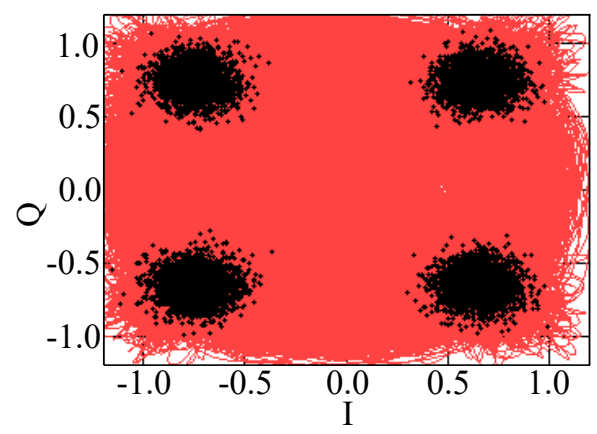

(d)

Figure 8. 4-QAM constellation diagrams of ceiling light and different bandwidths: (a) 4-QAM, $\mathrm{BW}=1 \mathrm{MHz}$, (b) 4-QAM, BW = $2 \mathrm{MHz}$, (c) 4-QAM, BW = $3 \mathrm{MHz}$, (d) 4-QAM, BW = $4 \mathrm{MHz}$.

Figure 9 describes BER values of multiple channel widths and M-QAM modulation combinations. The graph itself also shows highest possible communication distance for measured modulation, which did not exceed BER threshold. The red line represents the FEC limit, so values exceeding it are beyond capabilities of fast error correction algorithms. Values located next to the arrows are BER.

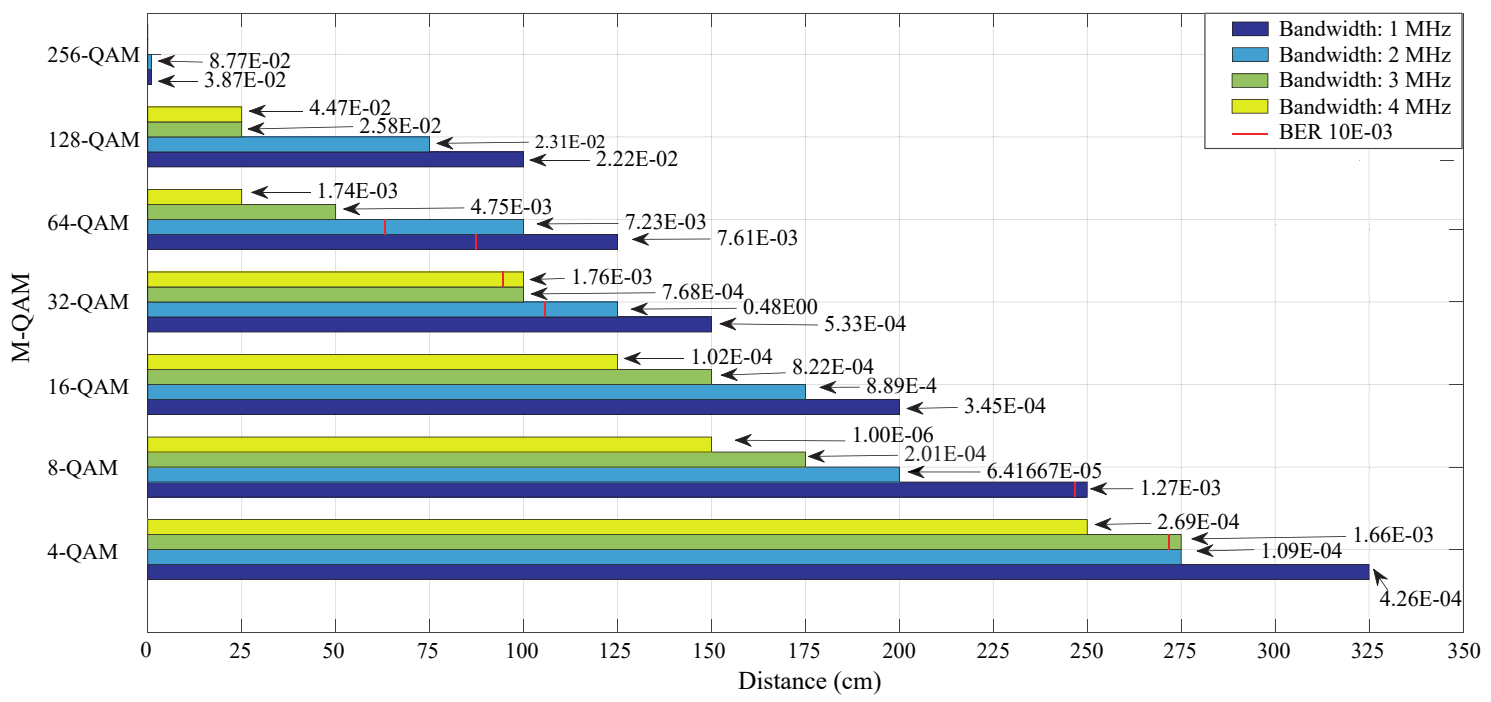

Figure 9. BER/distance from center relationship for ceiling light with different M-QAM and bandwidths.

Figures 10 and 11 represent a comparison of $1 \mathrm{MHz}$ and $4 \mathrm{MHz}$ channel widths, the highest and lowest measured variants. It is visible that $\mathrm{E}_{\mathrm{b}} / \mathrm{N}_{0}$ values slowly decreased with increasing measured 
distance. In comparison, EVM values shows opposite trend. Wider channels were also much more limited in maximal reachable operation distance, which is also visible on Figure 7 as well. Simpler modulation schemes in combination with narrow channel are much more robust, which is visible on Figure 9.

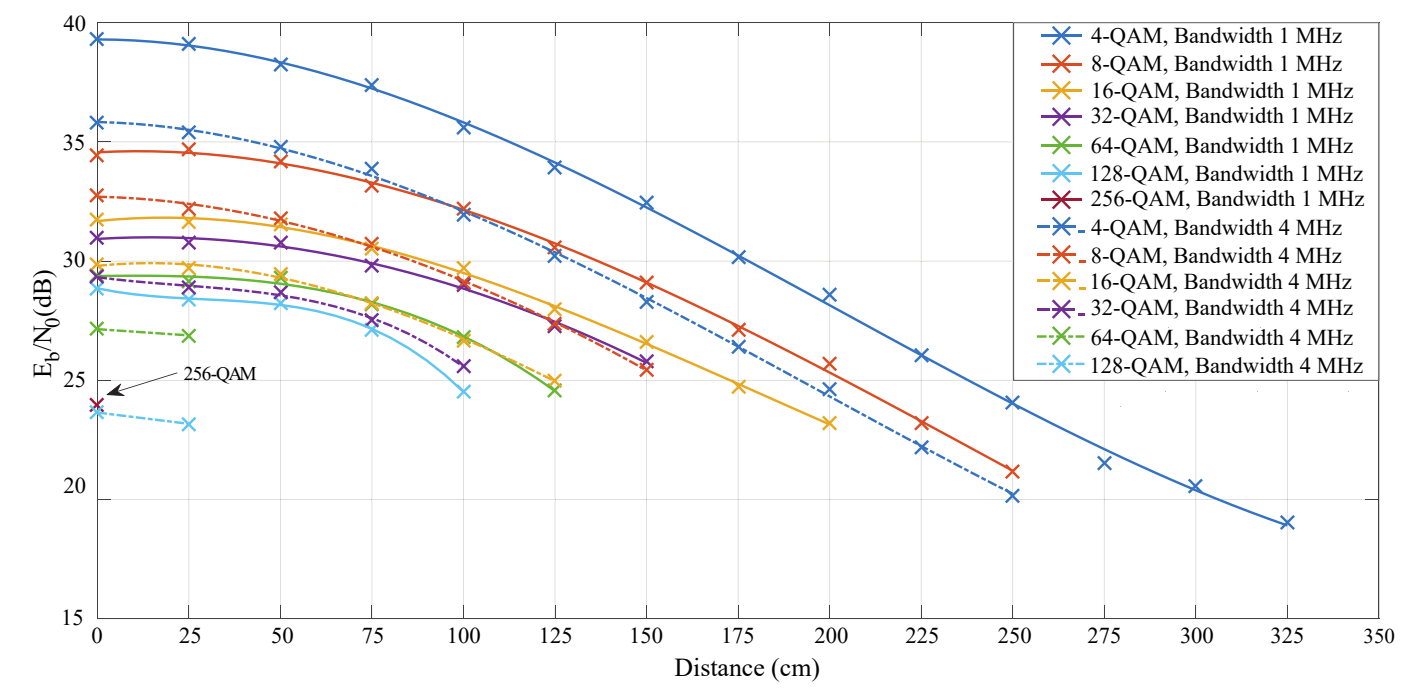

Figure 10. $\mathrm{E}_{\mathrm{b}} / \mathrm{N}_{0} /$ distance from center relationship for ceiling light with different M-QAM and bandwidths.

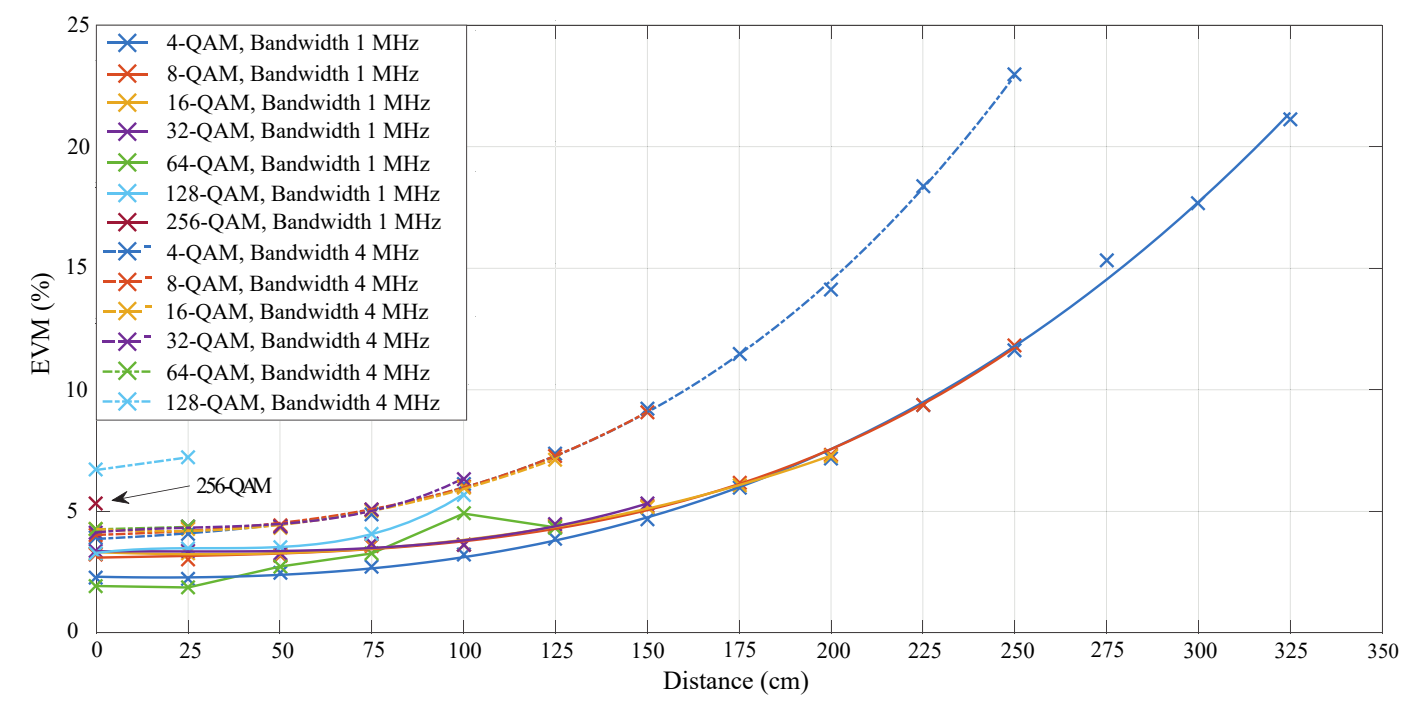

Figure 11. EVM/distance from center relationship for ceiling light with different M-QAM and bandwidths.

\section{A Feasibility Study on Outdoor Visible Light Communication: Car Tail-Light}

Measurements using car tail-light were carried out in multiple meteorological conditions. We approached this problem differently, as in real-life scenarios, meteorological conditions tend to often vary. These conditions were simulated in a plastic box made of plexiglass with dimensions of $50 \times 50 \times 500 \mathrm{~cm}$. Maximal measured distance in this scenario was $550 \mathrm{~cm}$, which was effective threshold for functional communication. The first step was to measure the empty box as reference values for future comparisons. After that, three scenarios were simulated: fog, thermal turbulence and rain. These scenarios will be discussed further in this paper. 
Figure 12 describes the tested setup, modified for Octavia tail-light. The whole experimental setup was very similar to the one used in ceiling light measurements. However, to carry out different scenarios the simulation box was inserted between transmitting light and receiving photodetector. Also using plano-convex lens was suitable for reaching higher RSL values and thus better transmit speed.

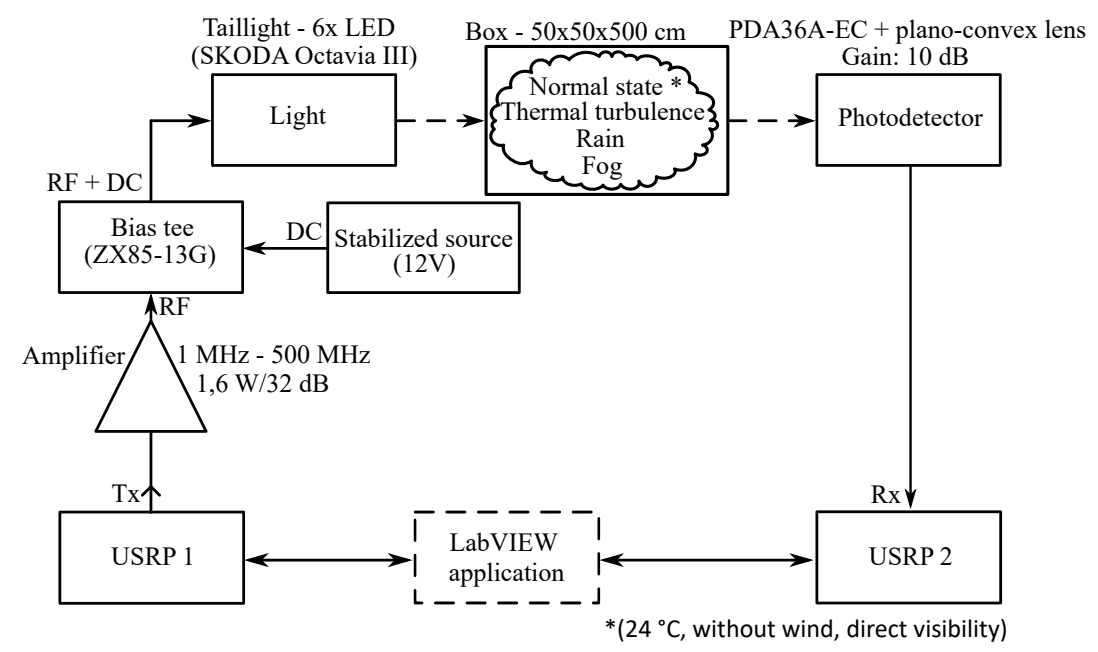

Figure 12. Octavia tail-light setup.

The following configuration was used in this scenario:

- Carrier frequency: $3 \mathrm{MHz}$

- $\quad$ Bandwidth: 1-4 MHz

- Modulation type: M-QAM

- TX/RX gain: $0 \mathrm{~dB}$

- Message symbols: 10,000

- Tx filter: root raised cosine

- Sample width: 16-bit

- Receiver-transmitter distance: $550 \mathrm{~cm}$

- Measured distance: 0-350 cm (step of $25 \mathrm{~cm}$ )

- Photodetector with planoconvex lens $\rightarrow$ more suitable for this scenario

- $\quad$ Measured parameters: $\mathrm{E}_{\mathrm{b}} / \mathrm{N}_{0}, \mathrm{BER}, \mathrm{EVM}, \mathrm{MER}$

Table 3 shows parameters of LED - LA G6SP. A matrix of these LEDs is used in Octavia tail-lights.

Table 3. Parameters of LED - LA G6SP.

\begin{tabular}{ll}
\hline Technology & InGaAlP Thinfilm \\
Viewing angle at 50 \% IV & 120 (Lambertian Emitter) \\
Color & Red $(623 \mathrm{~nm})$ \\
Optical efficiency & $56 \mathrm{~lm} / \mathrm{W}$ \\
Operating temperature & from -40 to $110^{\circ} \mathrm{C}$ \\
Max surge current & $1000 \mathrm{~mA}$ \\
Max current & $140 \mathrm{~mA}$ \\
Typical voltage & $2.1 \mathrm{~V}$ \\
\hline
\end{tabular}

Each measurement consisted of attenuation characteristics, which were measured by a vector network analyzer. By comparing every scenario, it was visible that fog had the highest impact, followed by rain and thermal turbulence, as seen on Figure 13. Also, we have included a reference power level of laser needed for functional 4-QAM transmission in the fog scenario. 


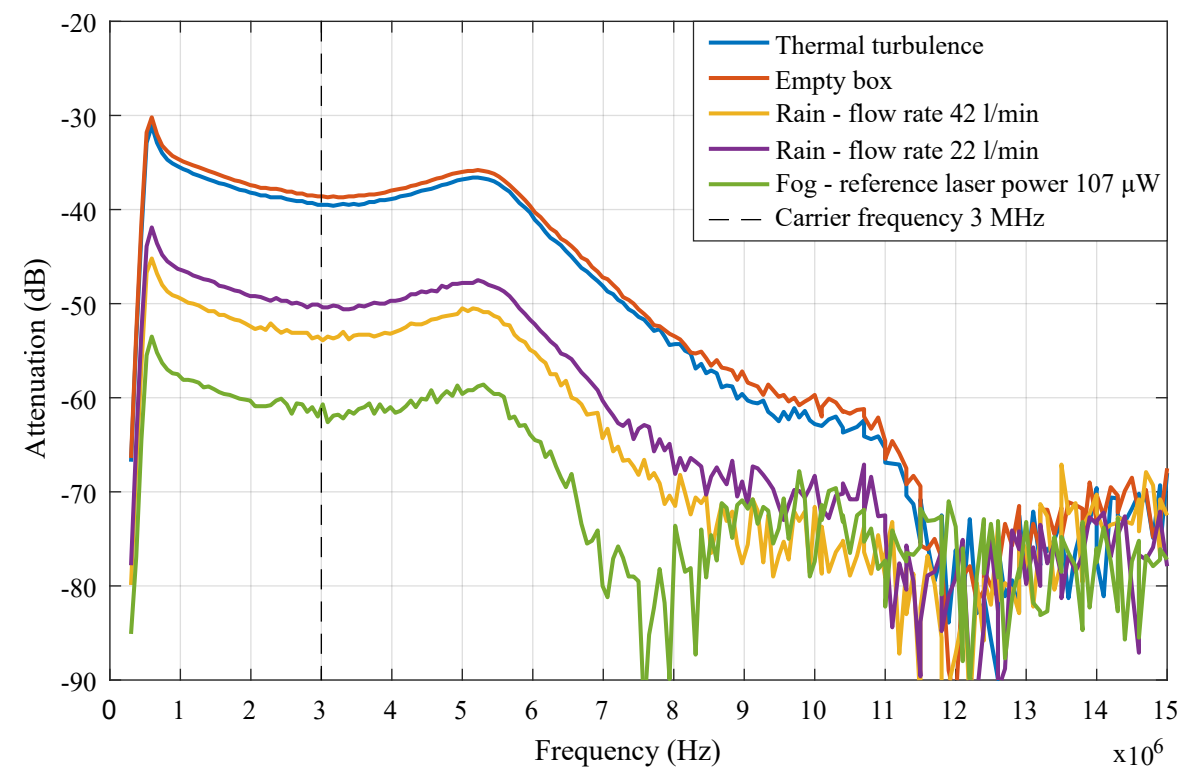

Figure 13. Attenuation characteristics of the Octavia tail-light.

Following measurements should cover most situations, which might happen in infrastructure-to-vehicle (I2V), V2V, V2I , V2N, V2P, V2D, V2G and V2H scenarios.

\subsection{Scenario 1-Empty Box}

As mentioned earlier, these measurements were used as reference values for further comparisons. To ensure conformity of measured data, these conditions were set as referential: $24^{\circ} \mathrm{C}$, direct visibility, windless. Setup can be seen in Figure 14.

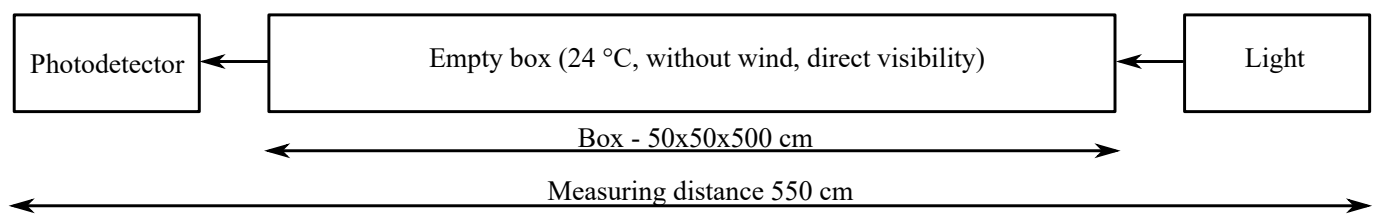

Figure 14. Octavia taillight setup adjusted for scenario 1—empty box.

Comparison of BER values with different bandwidths can be seen on Figure 15. It is noticeable that up to 64-QAM, BER values tended to stay below $10^{-5}$ threshold set earlier. On the contrary, 128-QAM and higher modulations suffered from much higher BER values. Bit error ratio of 256-QAM was even below $10^{-2}$ in every bandwidth combination. These values were too high for FEC and communication is impossible in these conditions. Figures 16 and 17 describe $E_{b} / N_{0}$ and EVM values for every M-QAM and bandwidth combination. It is noticeable that starting from 256-QAM modulation, the difference between each bandwidth tended to increase rapidly. 


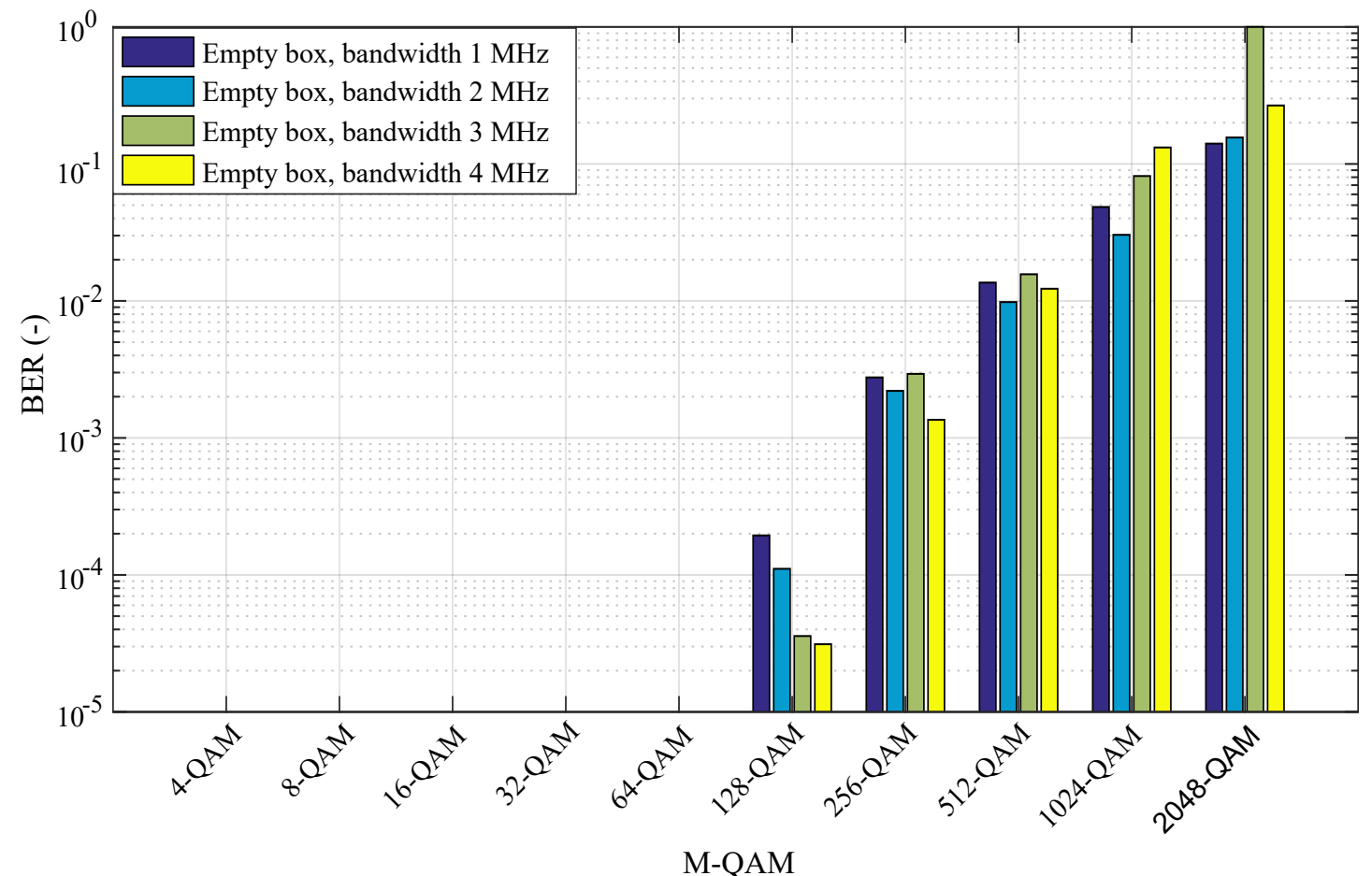

Figure 15. BER/distance relationship for Octavia tail-light with different M-QAM and bandwidths -scenario 1-empty box.

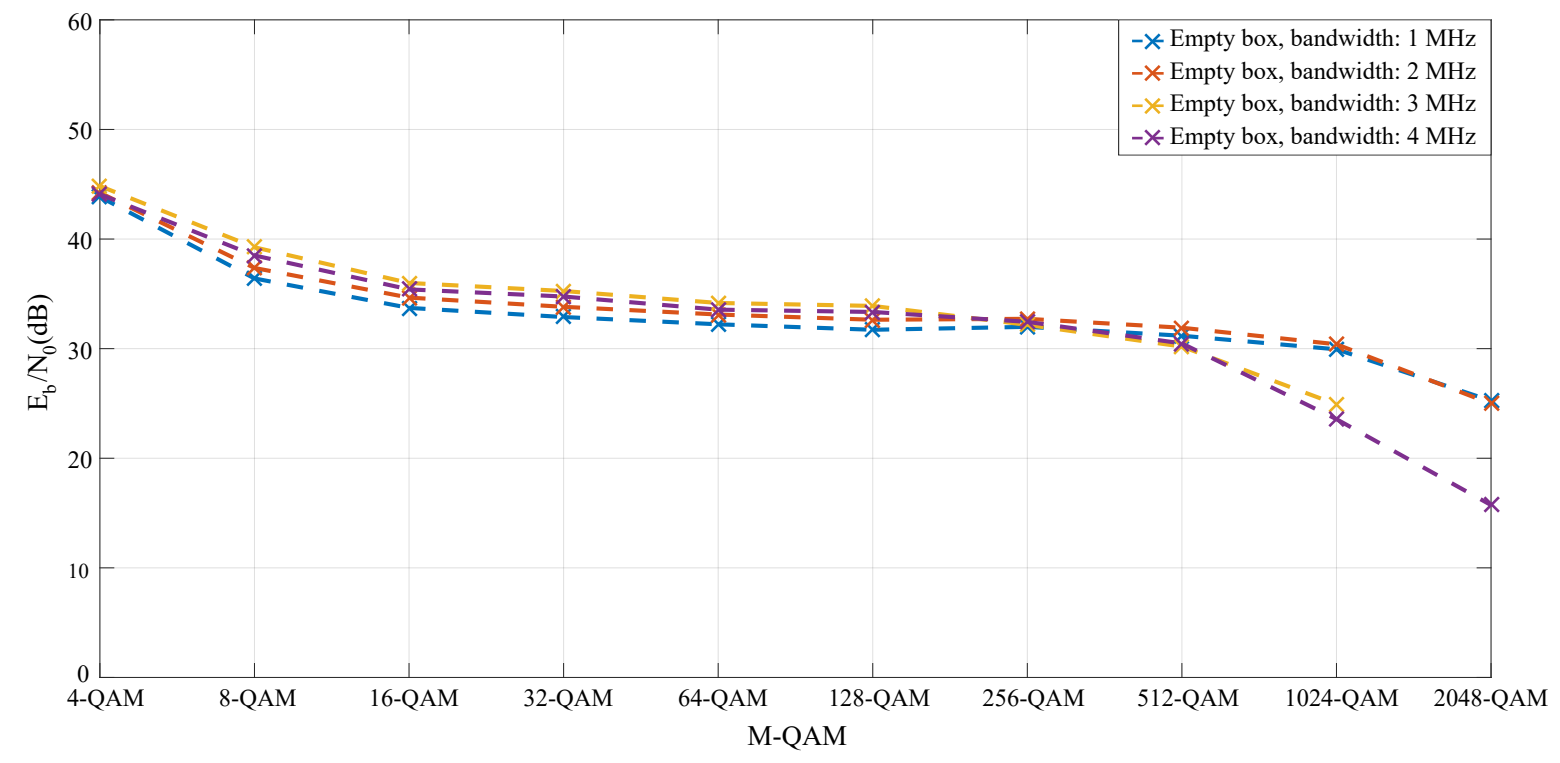

Figure 16. $\mathrm{E}_{\mathrm{b}} / \mathrm{N}_{0} /$ distance relationship for Octavia tail-light with different M-QAM and bandwidths -in scenario 1 -empty box. 


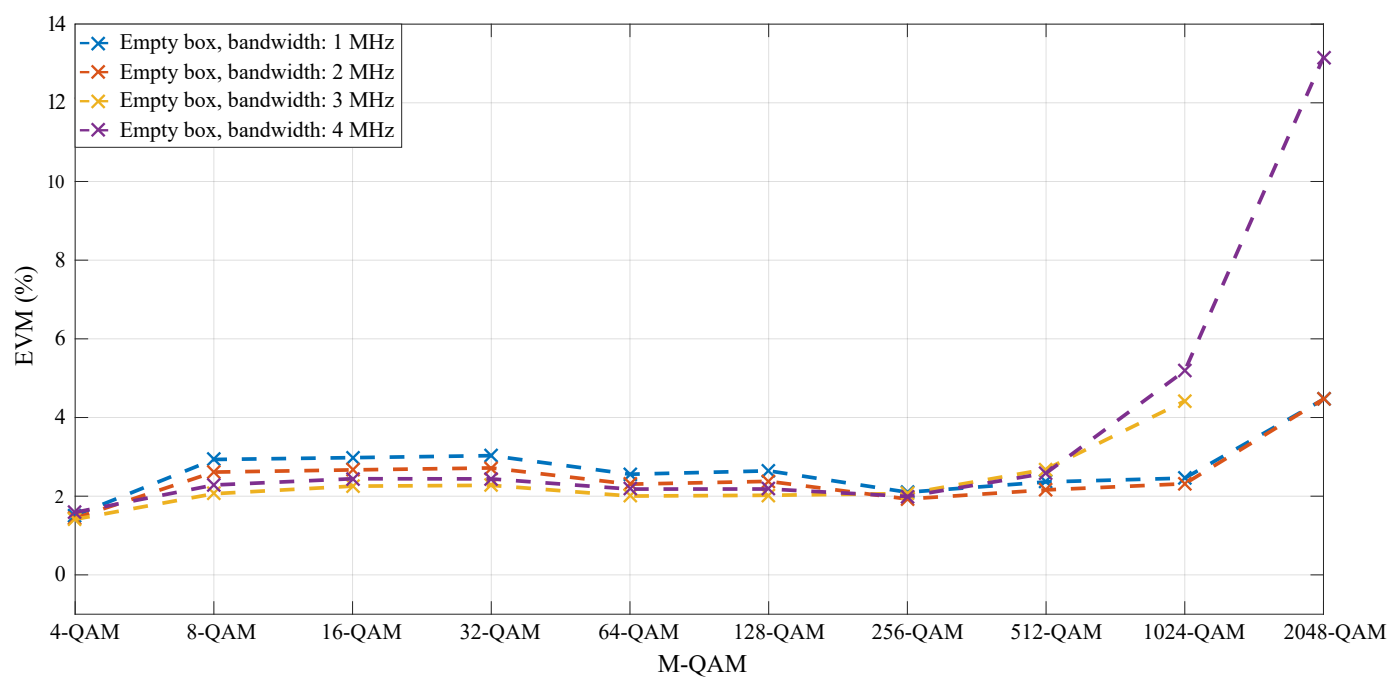

Figure 17. EVM/distance relationship for Octavia tail-light with different M-QAM and bandwidths—in scenario 1 -empty box.

\subsection{Scenario 2-Thermal Turbulence}

Measurements with thermal turbulence were carried out with modified box. The bottom part was removed, and multiple hot-air blowers were mounted instead. The top part of box was perforated to ensure sufficient air flow. Each blower heated the air to $50{ }^{\circ} \mathrm{C}$. Heated air then steadily flowed through box and slowly cooled to $44^{\circ} \mathrm{C}$, which were measured directly at perforations. The horizontal airflow was $0.3 \mathrm{~m} / \mathrm{s}$ and vertical was $2.5 \mathrm{~m} / \mathrm{s}$. Whole measurement was carried out multiple times until temperature inside box stabilized. Setup can be seen in Figure 18.

Comparison of BER values with different bandwidths can be seen in Figure 19. It is noticeable that up to 32-QAM, BER values tended to stay below $10^{-5}$. On the contrary, 64-QAM and higher modulations suffered from much higher BER. Figures 20 and 21 describe $E_{b} / N_{0}$ and EVM values for every M-QAM and bandwidth combination. By comparing these values to the reference, we can notice a slight decrease of $\mathrm{E}_{\mathrm{b}} / \mathrm{N}_{0}$ and increase of EVM values. The most significant changes began at 128-QAM and progressed further. Communication ceased to work, so 2048-QAM was not measurable.

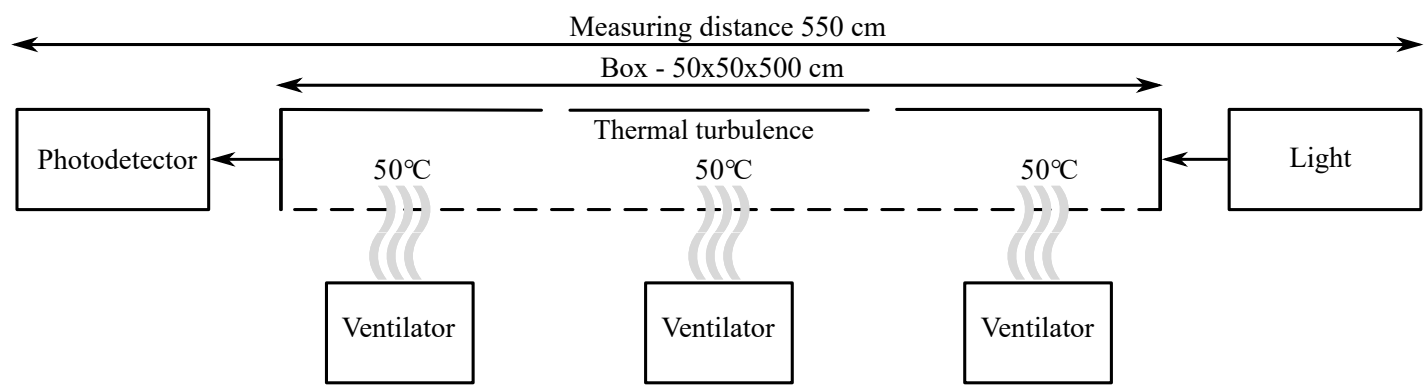

Figure 18. Octavia tail-light setup adjusted for scenario 2-thermal turbulence. 


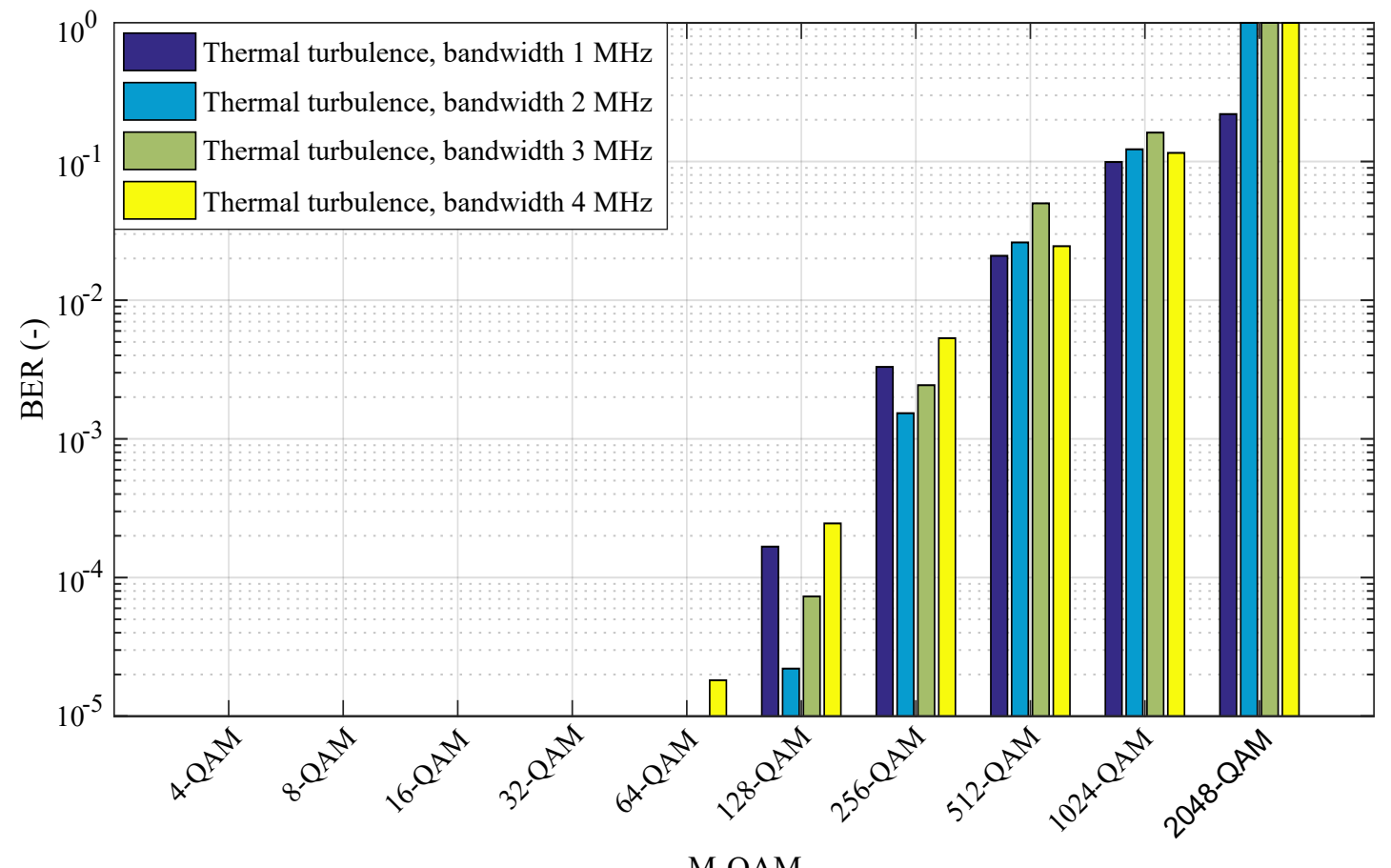

Figure 19. BER/distance relationship for Octavia tail-light with different M-QAM and bandwidths-scenario 2-thermal turbulence.

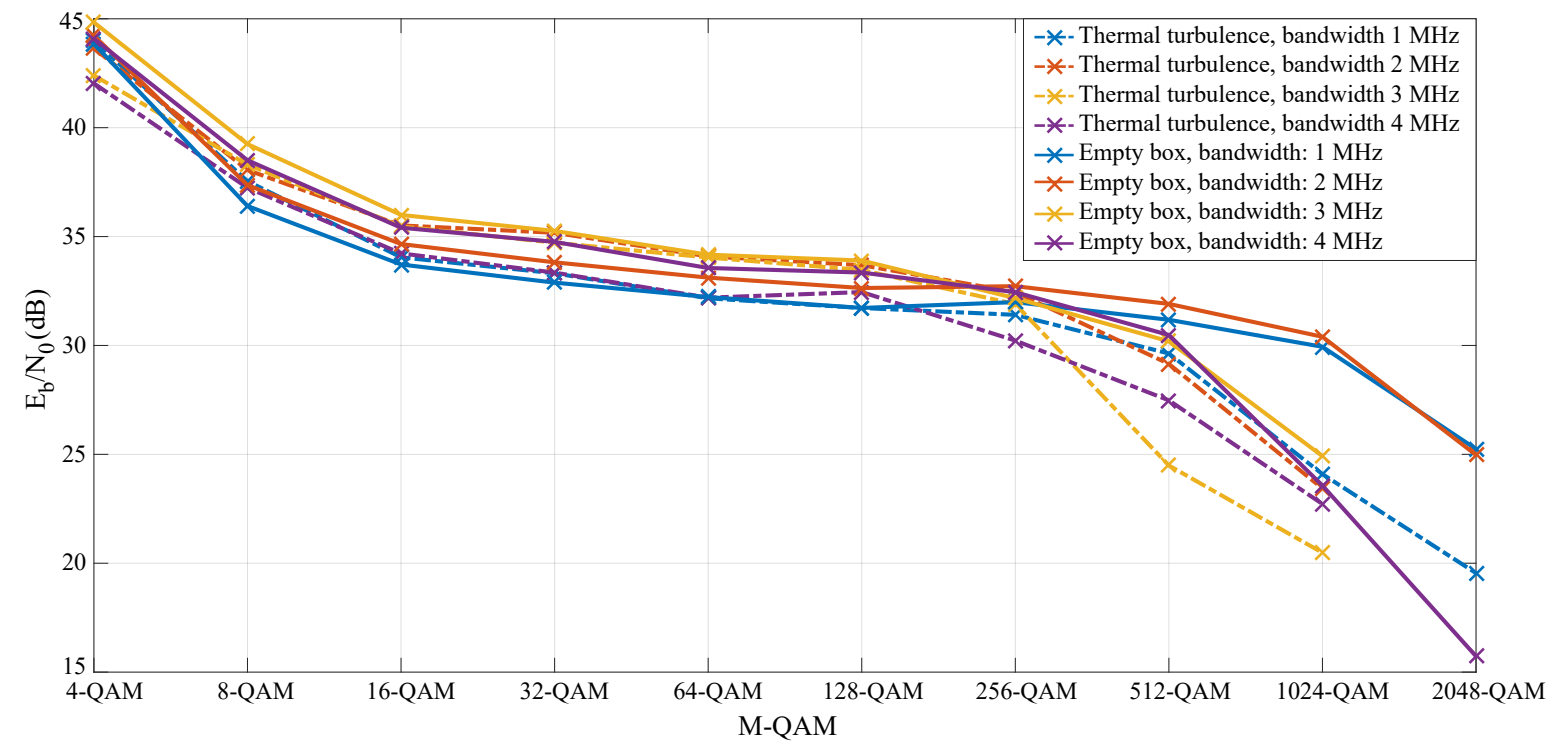

Figure 20. $\mathrm{E}_{\mathrm{b}} / \mathrm{N}_{0} /$ distance relationship for Octavia tail-light with different M-QAM and bandwidths-scenario 2-thermal turbulence. 


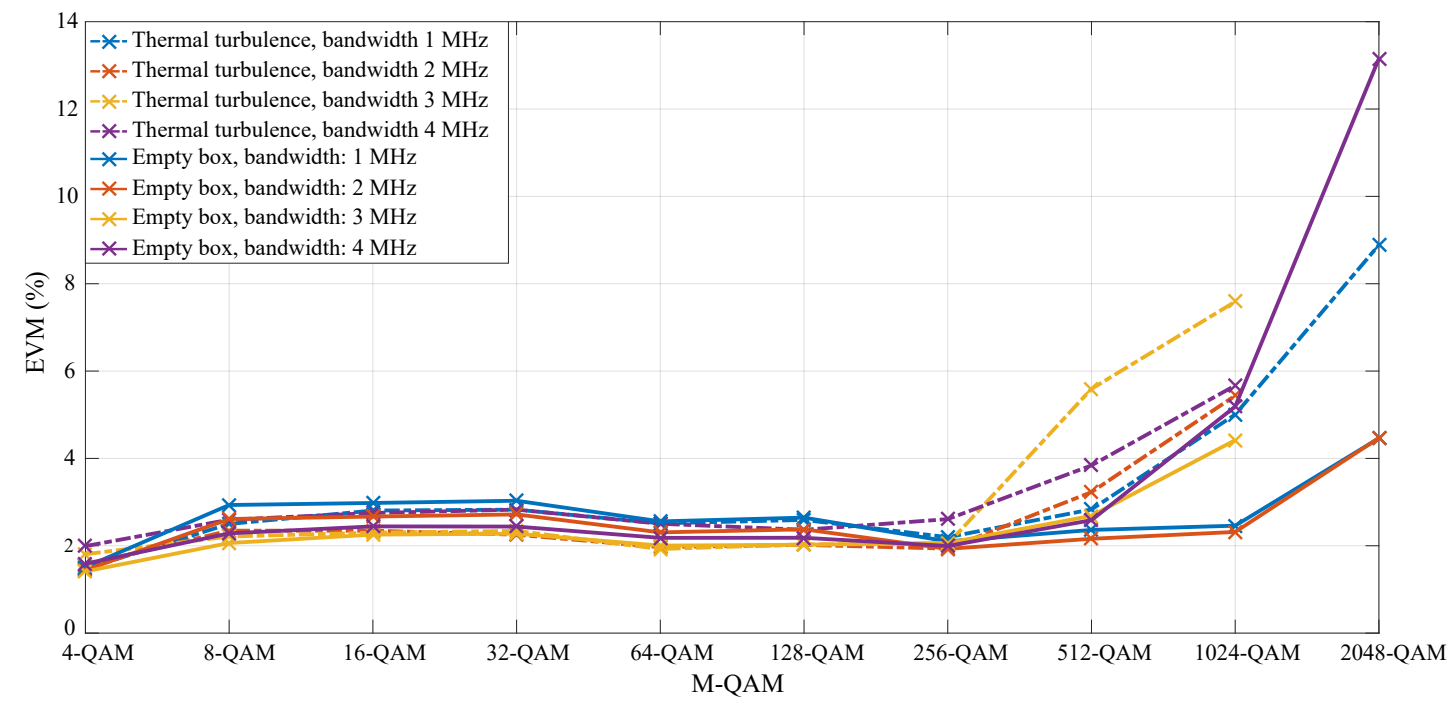

Figure 21. EVM/distance relationship for Octavia tail-light with different M-QAM and bandwidths-scenario 2-thermal turbulence.

\subsection{Scenario 3-Rain $42 \mathrm{~L} / \mathrm{min}$}

The first part of measurements with rain were carried out in modified box as well. In this scenario, we have removed the top part of the box and exchanged it with three water nozzles. The box was equipped with compressor which pumped water from the bottom of the box back into nozzles. The transmitter and receiver were located outside the box, which was opened from both sides. In this scenario, the water flow was set to $42 \mathrm{~L} / \mathrm{min}$. Setup can be seen on Figure 22. Figure 23 shows a photo of this setup.

Measurements were carried out in a room at $22-25{ }^{\circ} \mathrm{C}$. Water temperature was stabilized at $22-25^{\circ} \mathrm{C}$ before each measurement. Both transmitter and receiver were located $25 \mathrm{~cm}$ from open side of the box. This way, it was impossible for them to get fogged up. To investigate the influence of walls or partitions a series of tests without a box and in a completely dark room were carried out before. The box had minimal influence, as its construction was adjusted to prevent it. Transmitting light was precisely focused into the box to avoid interference, which could be caused by possible reflections. Incoming light was also focused into photodetector by planoconvex lens, as mentioned earlier. Box construction was spacious enough to avoid unnecessary reflections on running water. However, the influence of water particles on detector/transmitter itself will definitely be a topic of further research.

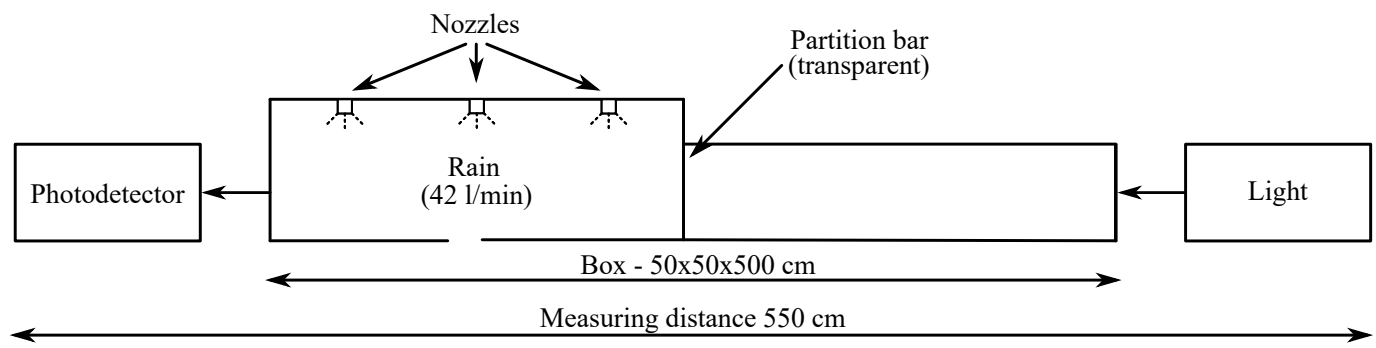

Figure 22. Octavia tail-light setup adjusted for scenario 3-Rain $42 \mathrm{~L} / \mathrm{min}$. 


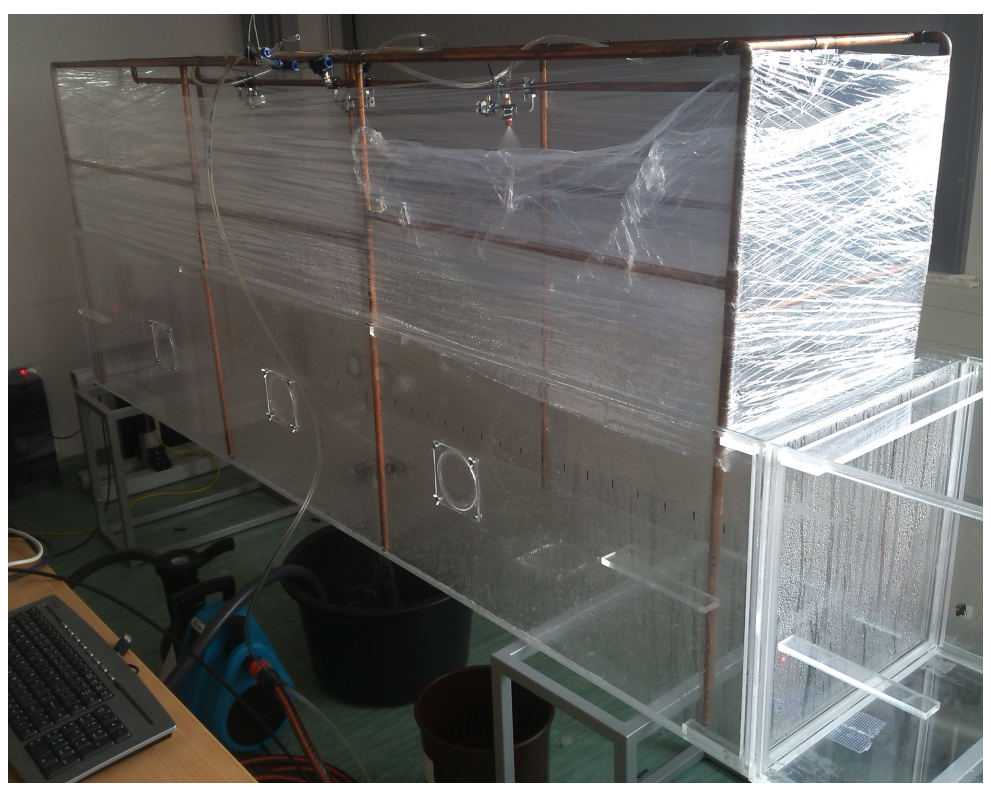

Figure 23. Photo of setup for scenario 3 and 4-rain.

Comparison of BER values with different bandwidths can be seen on Figure 24. This time, up to 8-QAM, BER stayed below $10 \mathrm{e}^{-5}$. On the contrary, 16-QAM and higher modulations suffer from much higher BER.

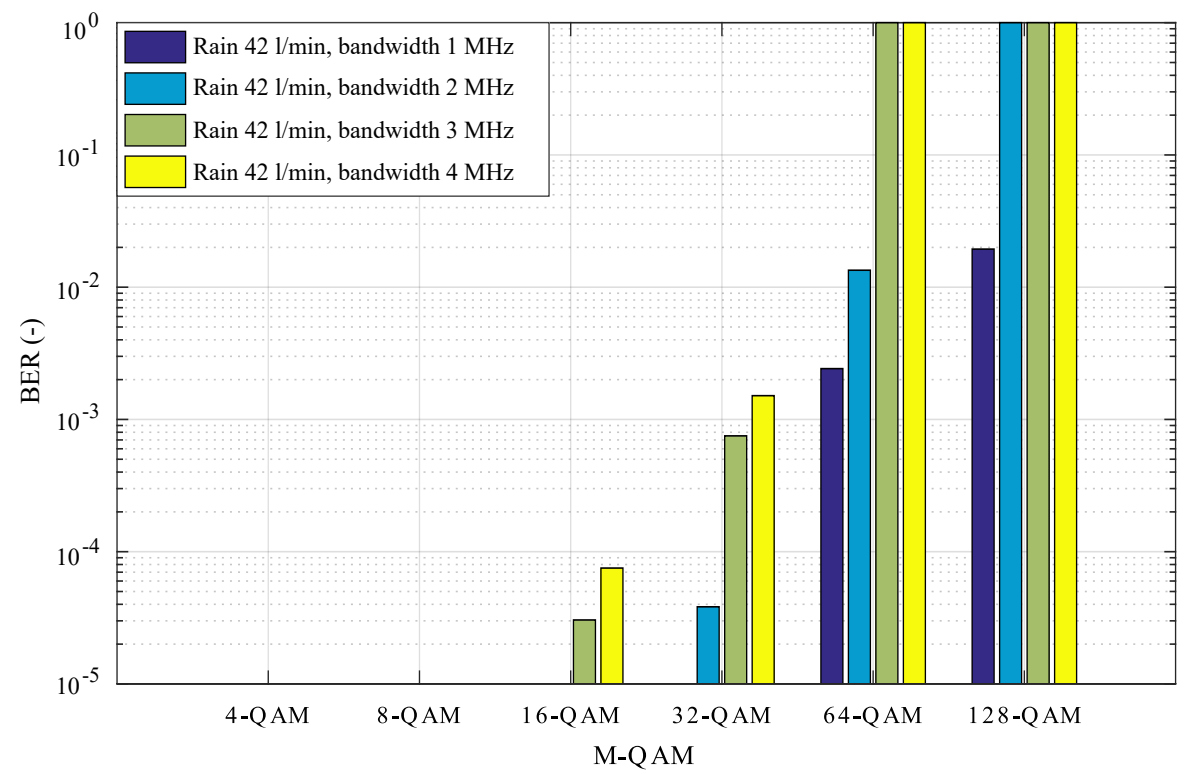

Figure 24. BER/distance relationship for Octavia tail-light with different M-QAM and bandwidths—scenario 3-Rain $42 \mathrm{~L} / \mathrm{min}$.

$\mathrm{E}_{\mathrm{b}} / \mathrm{N}_{0}$ and EVM values are displayed on Figures 25 and 26. By comparing these values to reference setup, there was a significant drop in signal quality. For example, in case of 4-QAM modulation and $1 \mathrm{MHz}$ bandwidth, SNR was nearly $10 \mathrm{~dB}$ lower than the reference. Significant decrease in signal quality was observed, which also led to lower maximal reachable modulation/bandwidth combination, which was 128-QAM/1 MHz. 


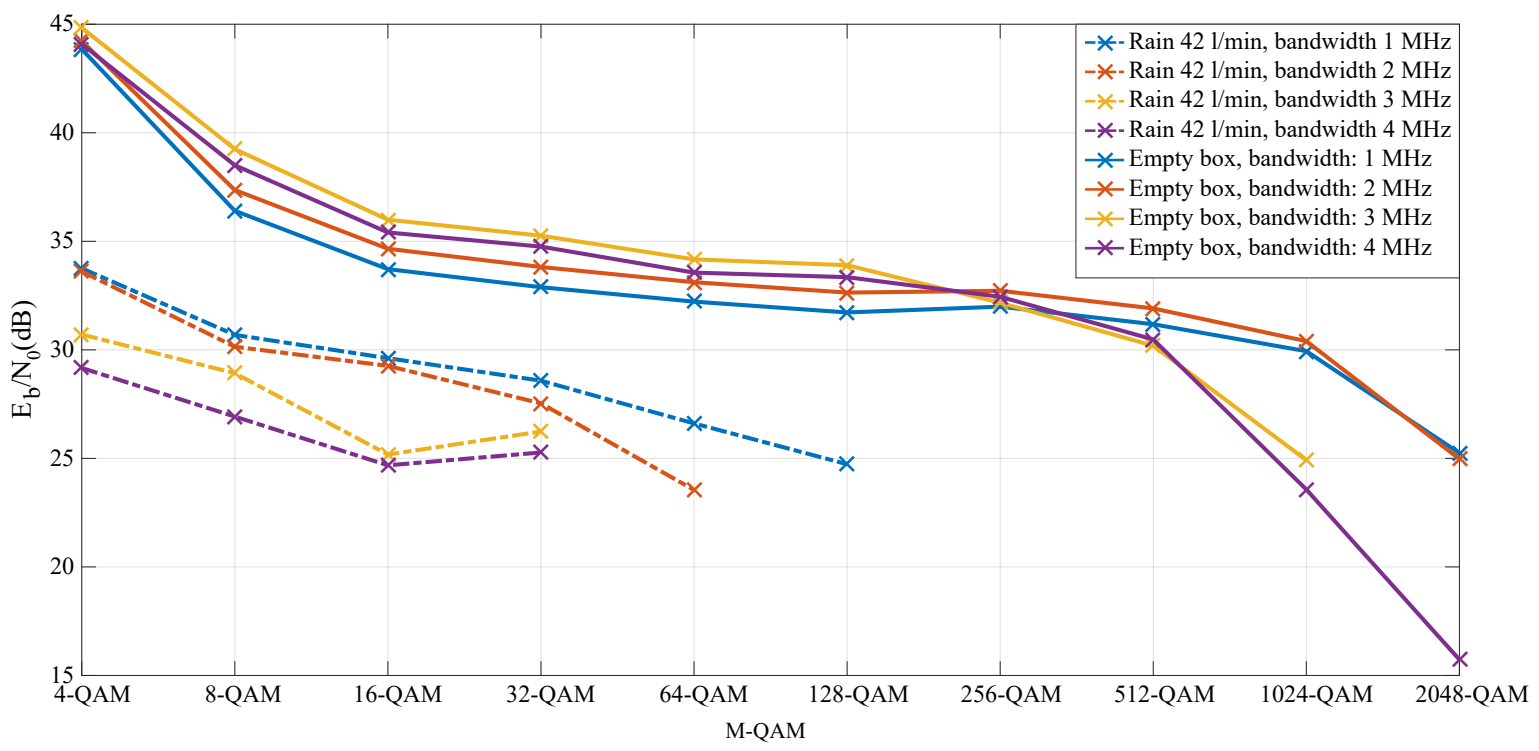

Figure 25. $\mathrm{E}_{\mathrm{b}} / \mathrm{N}_{0} /$ distance relationship for Octavia tail-light with different M-QAM and bandwidths -scenario 3-Rain $42 \mathrm{~L} / \mathrm{min}$.

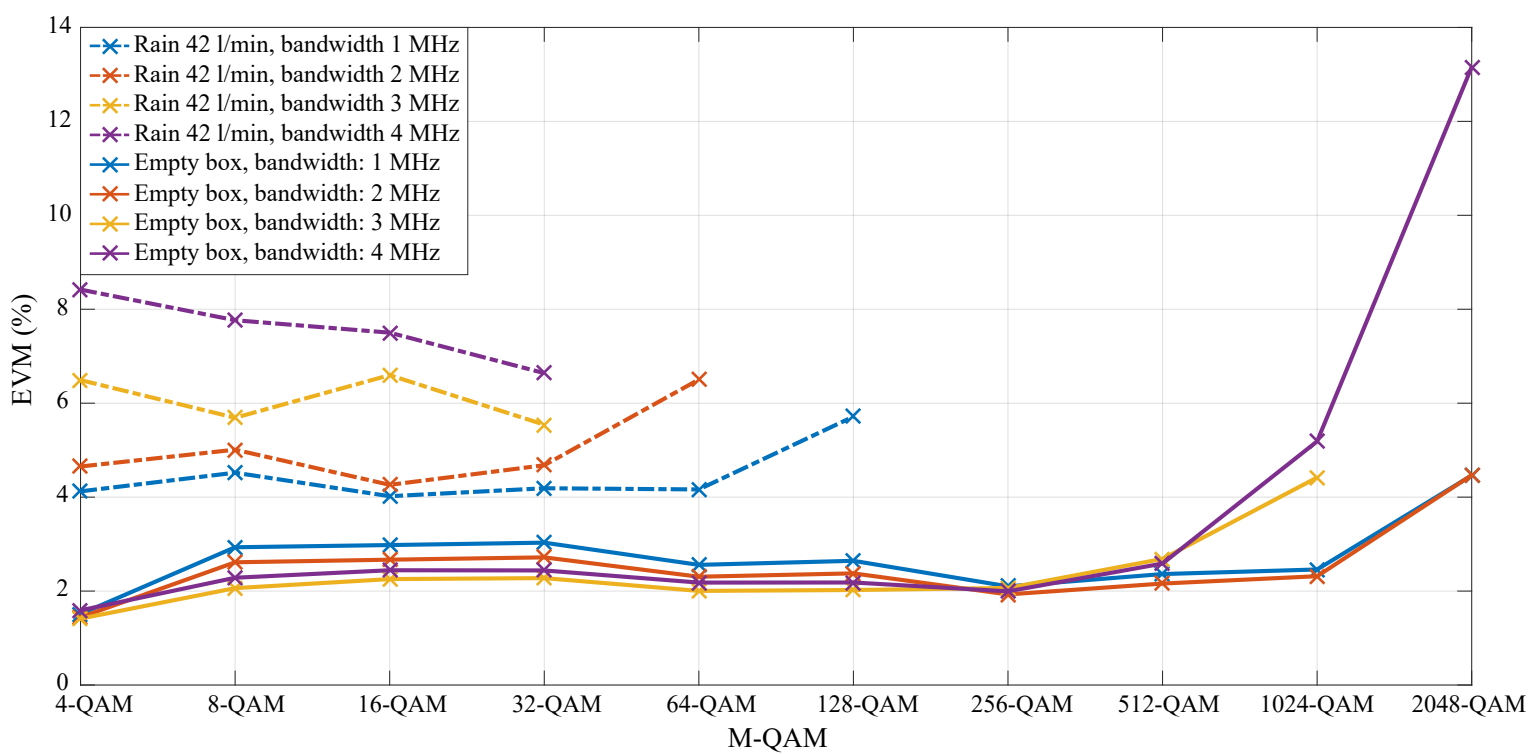

Figure 26. EVM/distance relationship for Octavia tail-light with different M-QAM and bandwidths -scenario 3-Rain $42 \mathrm{~L} / \mathrm{min}$.

This setup was also influenced by the drops of water on the sides of the box. Mainly the "separation wall" between box sections caused concerns. To analyze this concerning issue, we have carried out several measurements with different box setups, which can be seen on Figure 27. The first curve corresponds to the empty box, second one to the box with rain but without partition and the last one was the original measured setup. By comparing these values, there is a noticeable $3 \mathrm{~dB}$ increase in attenuation between second and third curve. 


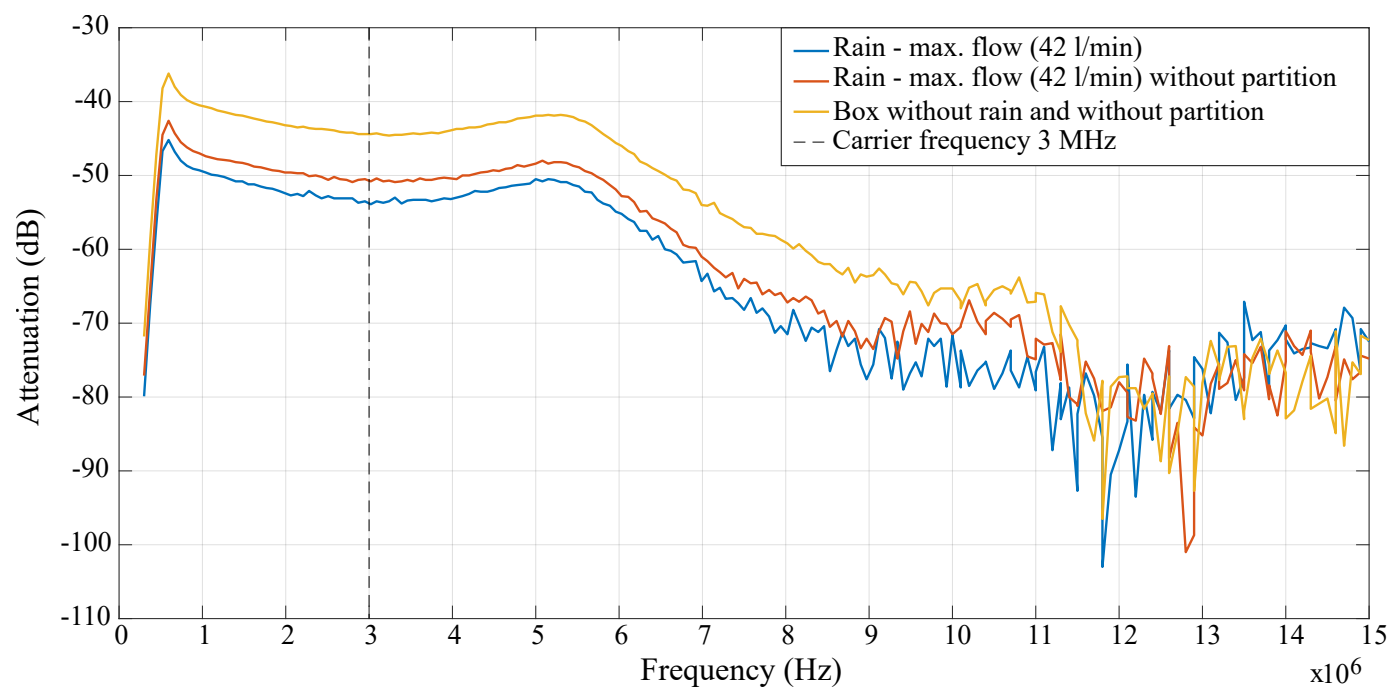

Figure 27. Attenuation characteristics of Octavia tail-light for scenario 3-Rain $42 \mathrm{~L} / \mathrm{min}$-comparison of intended setup and adjusted setup without partition.

\subsection{Scenario 4 -Rain $22 \mathrm{~L} / \mathrm{min}$}

The second part of measurements with rain were carried out in the modified setup from scenario 3 . The main difference was a different water flow of $22 \mathrm{~L} / \mathrm{min}$. Setup can be seen on Figure 28.

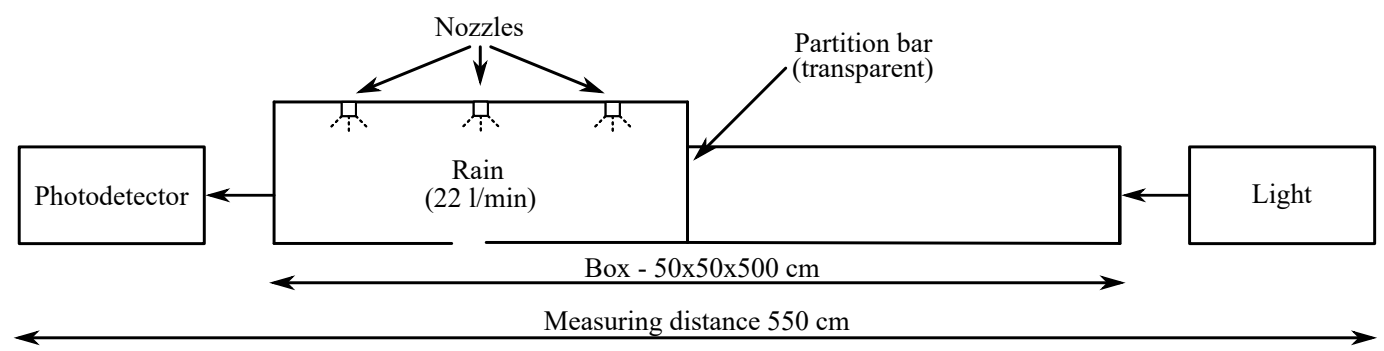

Figure 28. Octavia tail-light setup adjusted for scenario 4-Rain $22 \mathrm{~L} / \mathrm{min}$.

Comparison of BER values with different bandwidths can be seen on Figure 29. This time, up to 16-QAM, BER stayed below $10 \mathrm{e}^{-5}$. On the contrary, 32-QAM and higher modulations suffer from much higher BER.

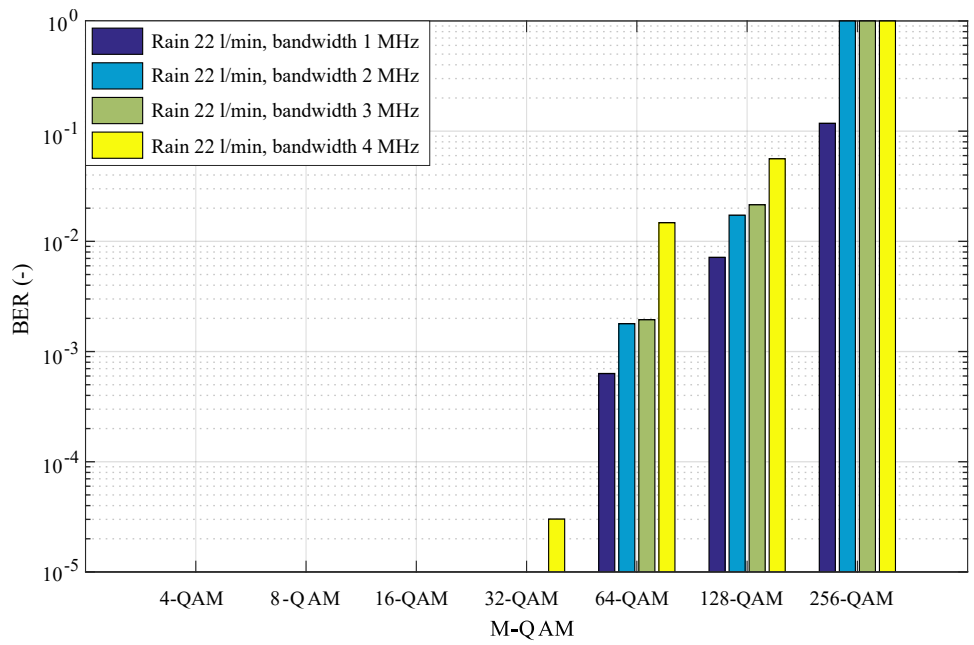

Figure 29. BER/distance relationship for Octavia tail-light with different M-QAM and bandwidths -scenario 4-Rain $22 \mathrm{~L} / \mathrm{min}$. 
$\mathrm{E}_{\mathrm{b}} / \mathrm{N}_{0}$ and EVM values (Figures 30 and 31 ) tended to follow the trend from previous scenario. This time, in case of 4-QAM modulation and $1 \mathrm{MHz}$ bandwidth, SNR is nearly $7 \mathrm{~dB}$ lower than the reference scenario 1 . Significant decrease in signal quality was observed, which also led to lower maximal reachable modulation/bandwidth combination, which was 256-QAM/1 MHz.

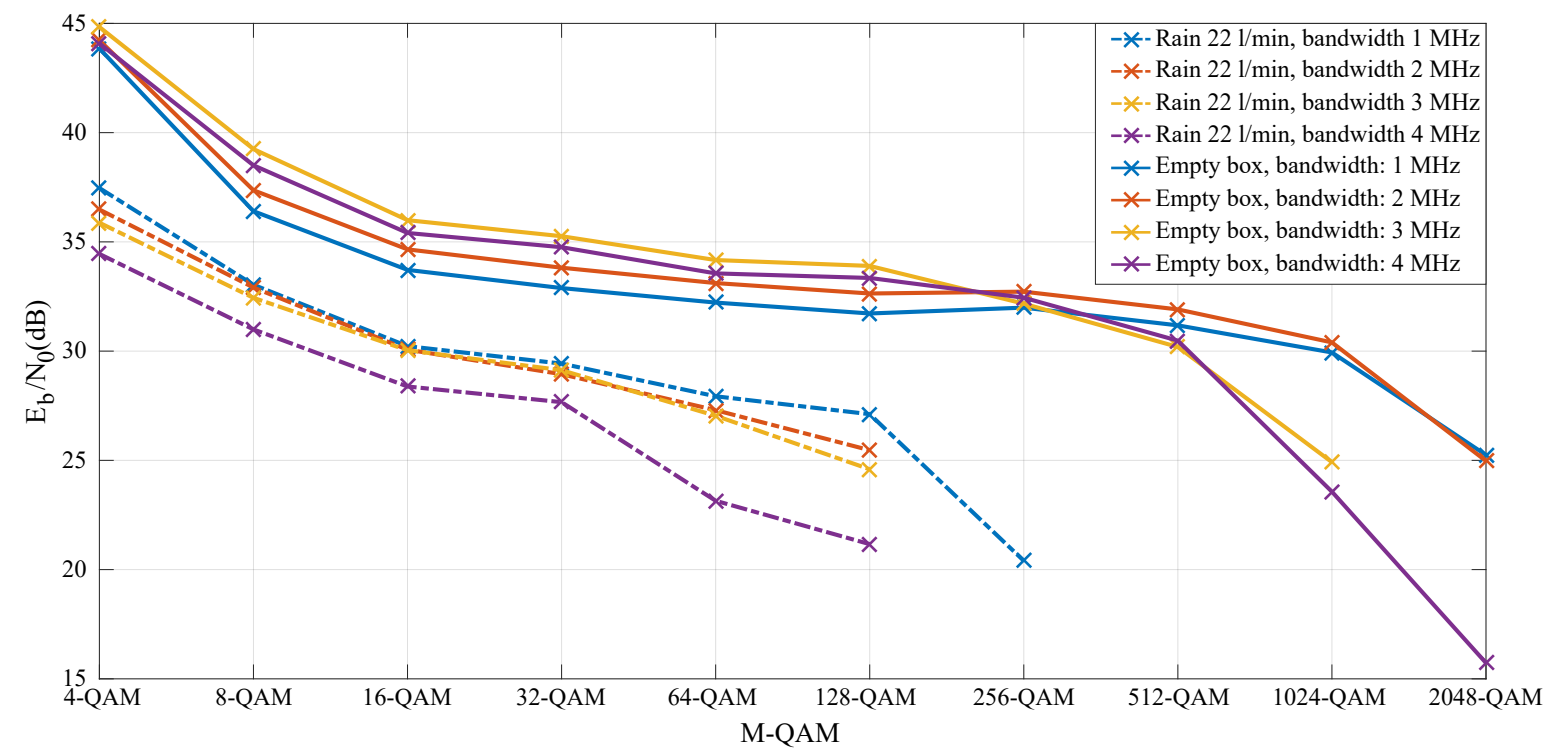

Figure 30. $E_{b} / N_{0} /$ distance relationship for Octavia tail-light with different M-QAM and bandwidths -scenario 4-Rain $22 \mathrm{~L} / \mathrm{min}$.

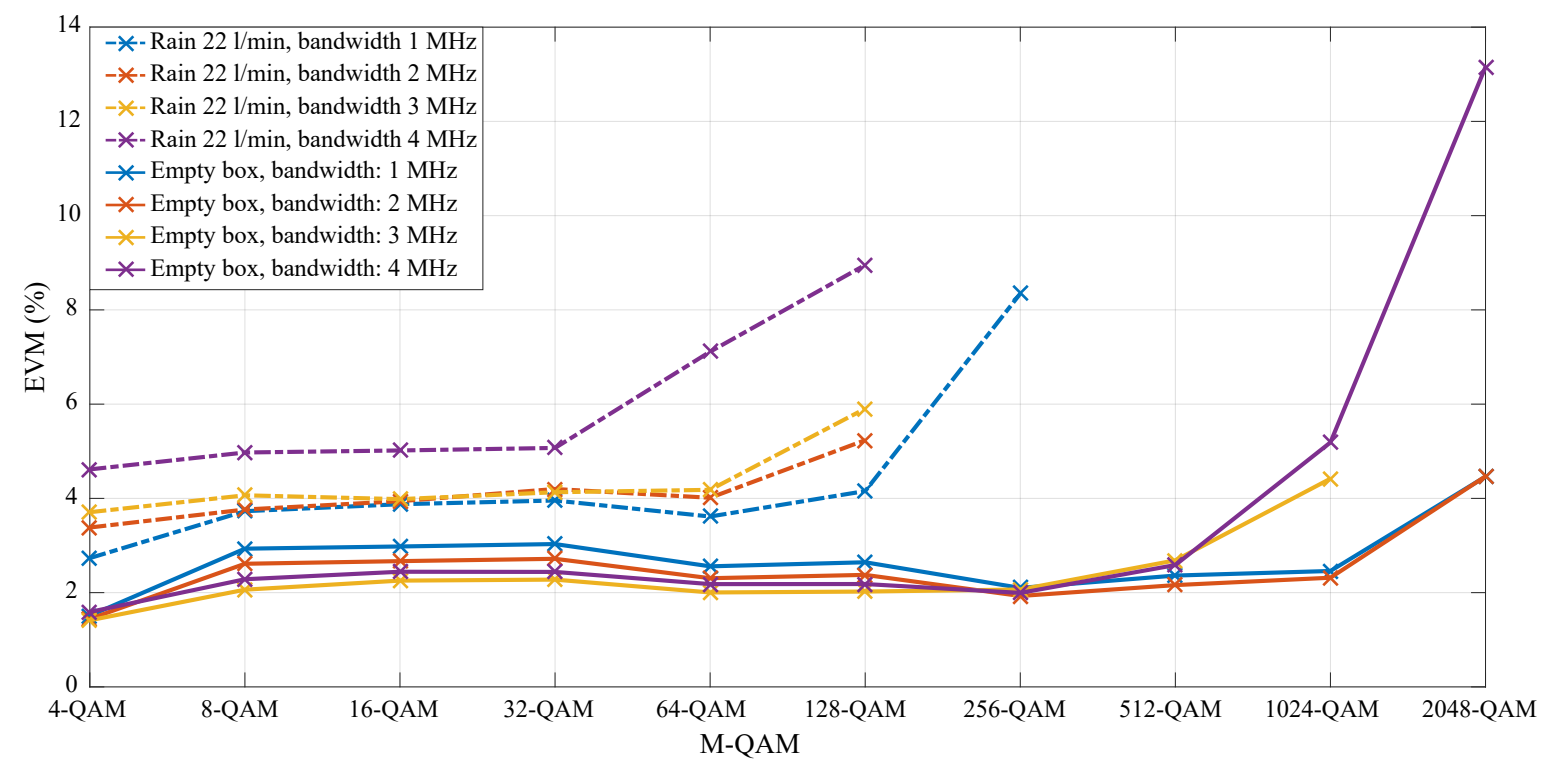

Figure 31. EVM/distance relationship for Octavia tail-light with different M-QAM and bandwidths -scenario 4-Rain $22 \mathrm{~L} / \mathrm{min}$.

Scenario 4 was also influenced by water drops. By carrying out the same test as in scenario 3 , we have measured a $4 \mathrm{~dB}$ difference in attenuation, which was caused by "partition bar"'. Measured values are displayed on Figure 32. 


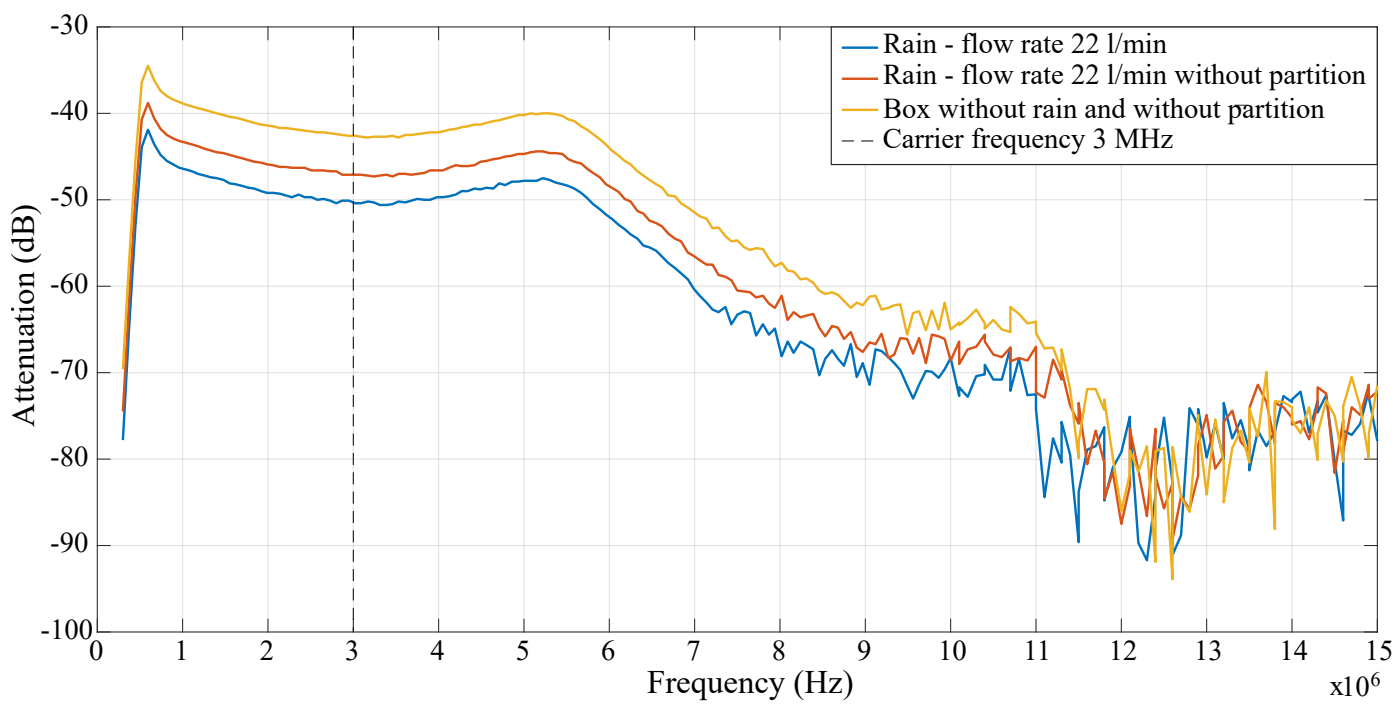

Figure 32. Attenuation characteristics of Octavia tail-light for scenario 4-Rain $22 \mathrm{~L} / \mathrm{min}$-comparison of intended setup and adjusted setup without partition.

\subsection{Scenario 5-Fog}

The last scenario consisted of a sealed box connected to the fog machine. This measurement differed from the others in that we did not always have the same conditions in the box, as fog inside gradually evaporated. That is why we had to add a $4 \mathrm{~mW}$ laser and optical power meter to our experiment (Figure 33). Figure 34 shows a photo of this setup. During measurements, we have monitored and gathered optical power levels to use them as reference values. Due to the slow fog evaporation, higher modulations gradually reached the desired BER threshold of $10^{-3}$. As soon as it happened, we carried out our main measurements. In this case we have measured all bandwidths at once, to preserve credibility. Figure 35 describes a slow dissipation of fog inside box with gathered laser optical power levels and BER values for $1 \mathrm{MHz}$ bandwidth.

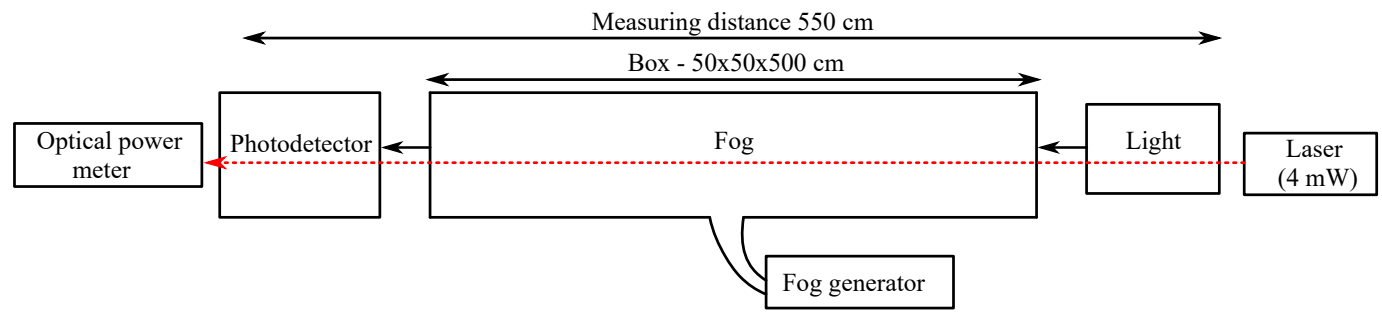

Figure 33. Octavia tail-light setup adjusted for scenario 5-fog.

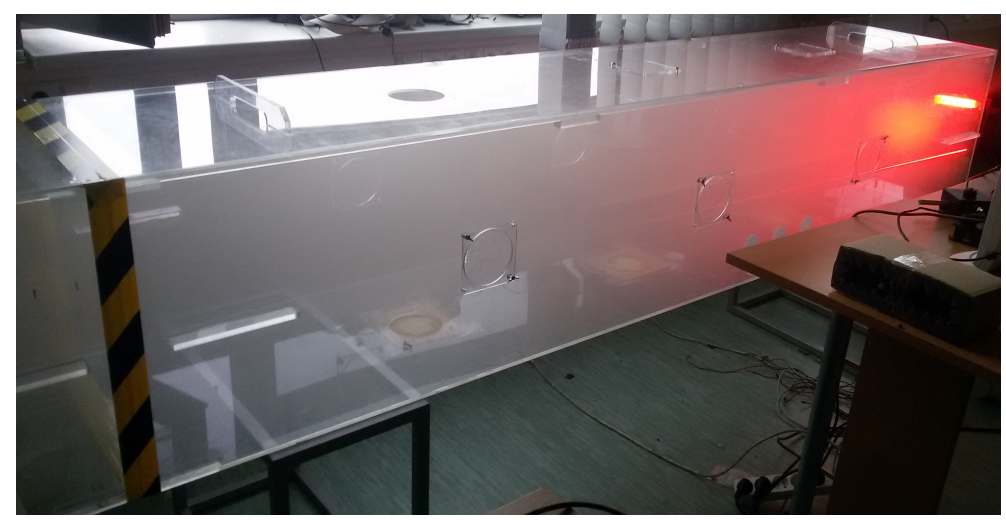

Figure 34. Photo of setup for scenario 5-fog. 


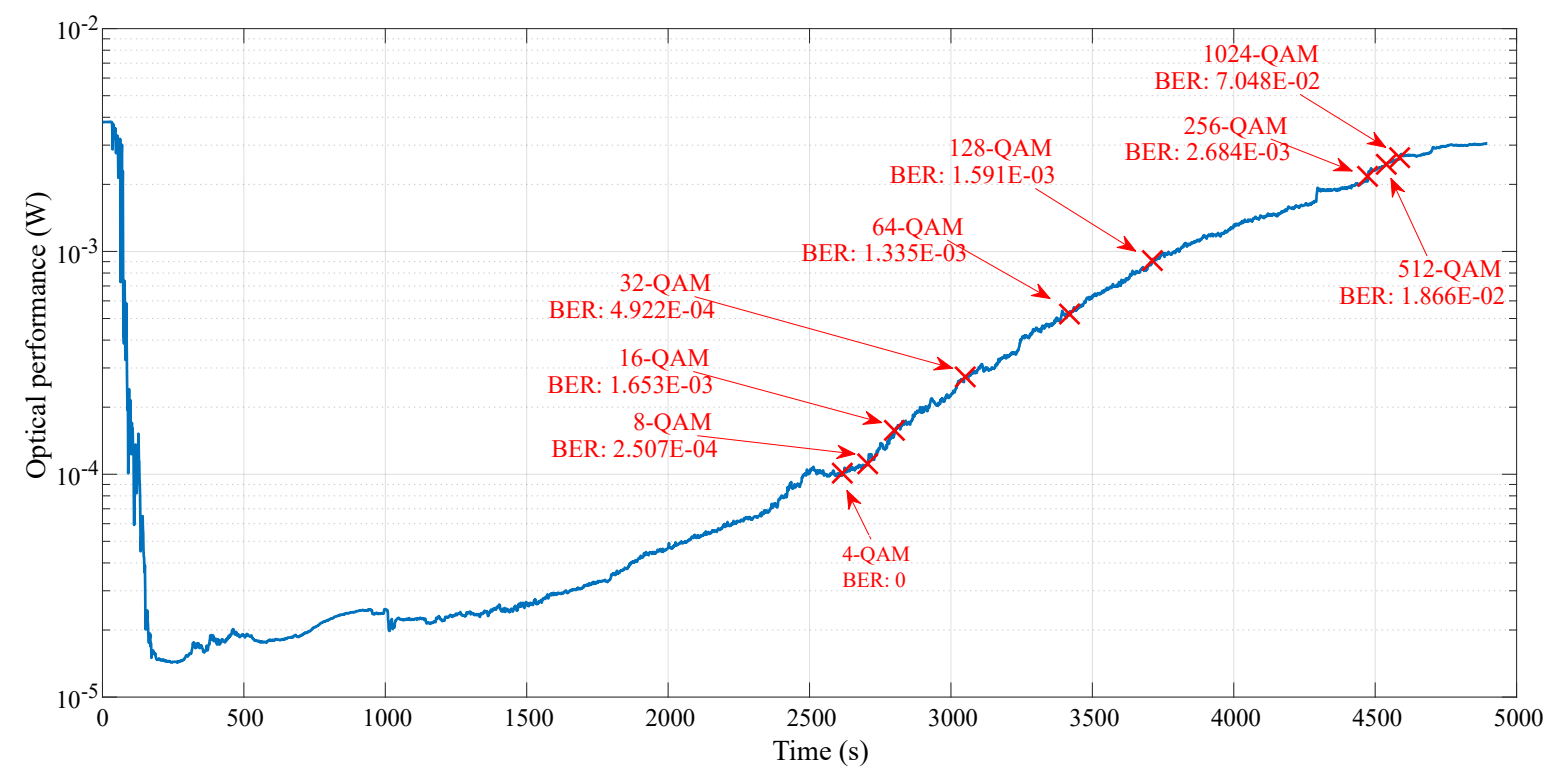

Figure 35. Fog dissipation with laser power levels and modulations with appropriate BER values.

The Laser itself was mainly used to exactly determine how fast the fog dissipated (concentration) and if it dissipated similarly in multiple measurements, which proved to be true. High directionality of laser beam and planoconvex lens on photodetector helped us to avoid any unnecessary effects of second light source. As mentioned the box was big enough to host both devices, which can work independently. In this case, the laser was the available device which we already had and could be used.

Table 4 consists of measured optical power level thresholds, after passing through fog. It is visible that at least a quarter of transmitted optical power is needed for higher modulation formats (128-QAM+) to work. That is why following the figures display minimal values for successful initiation of communication between transmitter and receiver for multiple modulation formats.

Table 4. Minimal optical power levels of laser for multiple bandwidth and modulations measured after passing through fog.

\begin{tabular}{ccccc}
\hline M-QAM & \multicolumn{4}{c}{ Bandwidth } \\
\hline - & $\mathbf{1 ~ M H z}$ & $\mathbf{2 ~} \mathbf{M H z}$ & $\mathbf{3} \mathbf{M H z}$ & $\mathbf{4 ~ \mathbf { M z }}$ \\
\hline 4-QAM & $101 \mu \mathrm{W}$ & $95 \mu \mathrm{W}$ & $97 \mu \mathrm{W}$ & $93 \mu \mathrm{W}$ \\
8-QAM & $112 \mu \mathrm{W}$ & $135 \mu \mathrm{W}$ & $175 \mu \mathrm{W}$ & $189 \mu \mathrm{W}$ \\
16-QAM & $154 \mu \mathrm{W}$ & $205 \mu \mathrm{W}$ & $250 \mu \mathrm{W}$ & $276 \mu \mathrm{W}$ \\
32-QAM & $275 \mu \mathrm{W}$ & $308 \mu \mathrm{W}$ & $463 \mu \mathrm{W}$ & $550 \mu \mathrm{W}$ \\
64-QAM & $525 \mu \mathrm{W}$ & $780 \mu \mathrm{W}$ & $930 \mu \mathrm{W}$ & $951 \mu \mathrm{W}$ \\
128-QAM & $905 \mu \mathrm{W}$ & $1.095 \mathrm{~mW}$ & $1.399 \mathrm{~mW}$ & $1.550 \mathrm{~mW}$ \\
256-QAM & $2.180 \mathrm{~mW}$ & $2.394 \mathrm{~mW}$ & $2.545 \mathrm{~mW}$ & $2.585 \mathrm{~mW}$ \\
512-QAM & $2.475 \mathrm{~mW}$ & $2.522 \mathrm{~mW}$ & $2.735 \mathrm{~mW}$ & $2.930 \mathrm{~mW}$ \\
1024-QAM & $2.640 \mathrm{~mW}$ & $2.955 \mathrm{~mW}$ & $3.120 \mathrm{~mW}$ & $3.172 \mathrm{~mW}$ \\
\hline
\end{tabular}

Measured BER values are displayed on Figure 36. This figure consists of all modulation formats, where BER values were better than 1 . However, it is necessary to compare these values to Table 4, as different optical power levels were needed for every modulation scheme. For example, at least a quarter of transmitted optical power had to be received for 128-QAM/2MHz combination to work. $\mathrm{E}_{\mathrm{b}} / \mathrm{N}_{0}$ and EVM values displayed on Figures 37 and 38 also must be compared to Table 4 . 


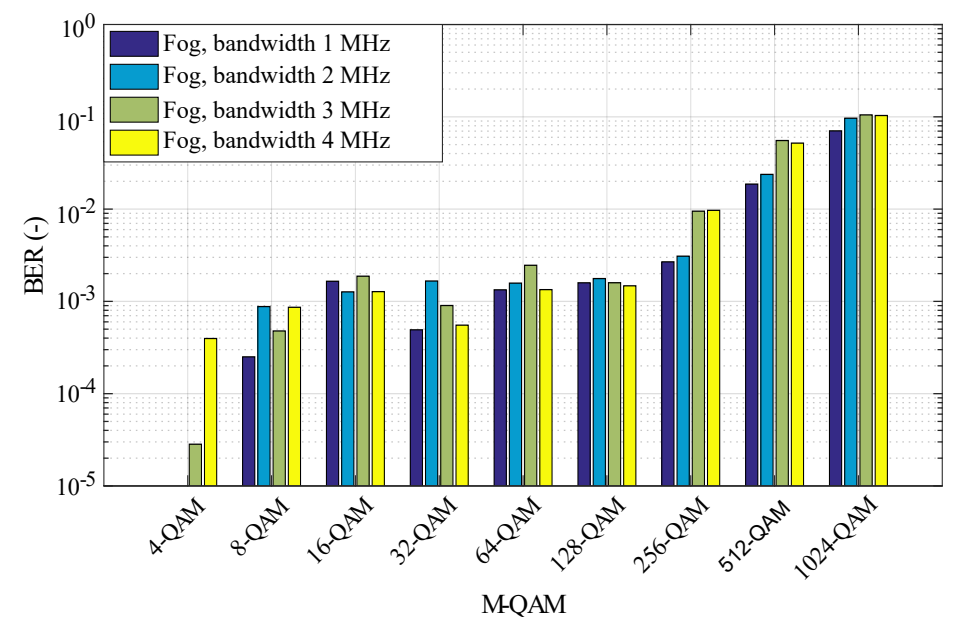

Figure 36. BER/distance relationship for Octavia tail-light with different M-QAM and bandwidths-in scenario 5 -fog.

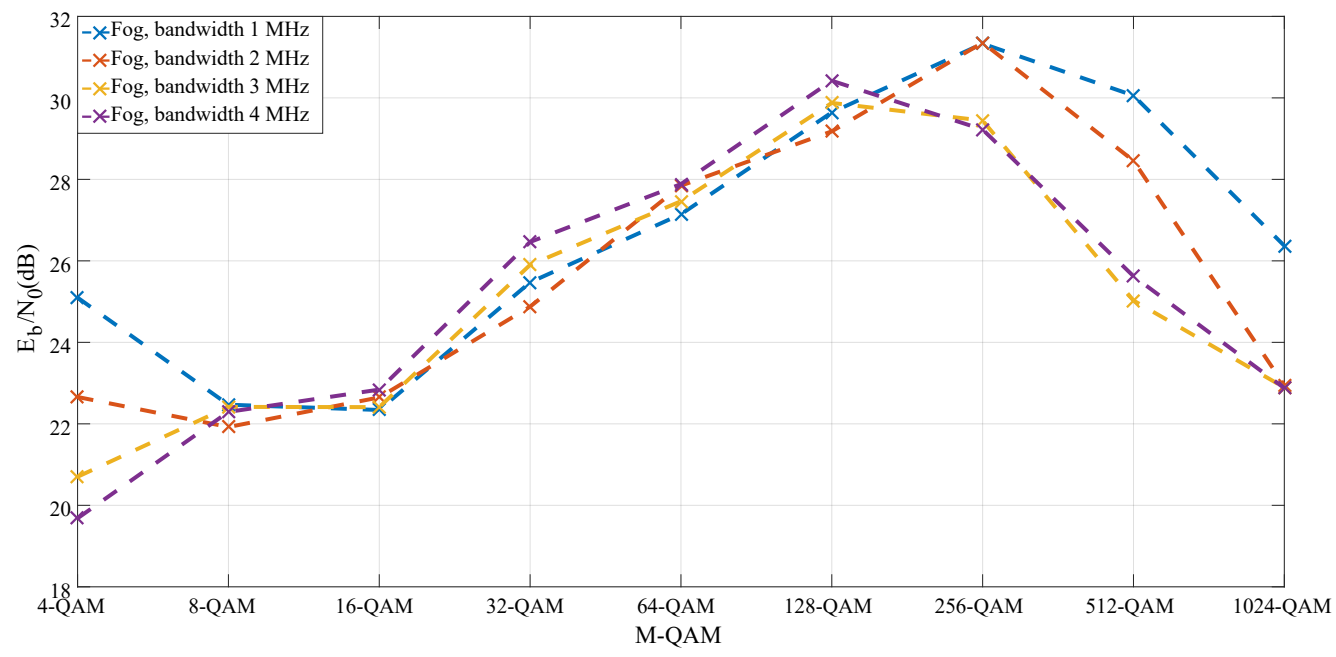

Figure 37. $\mathrm{E}_{\mathrm{b}} / \mathrm{N}_{0} /$ distance relationship for Octavia tail-light with different M-QAM and bandwidths -in scenario 5-fog.

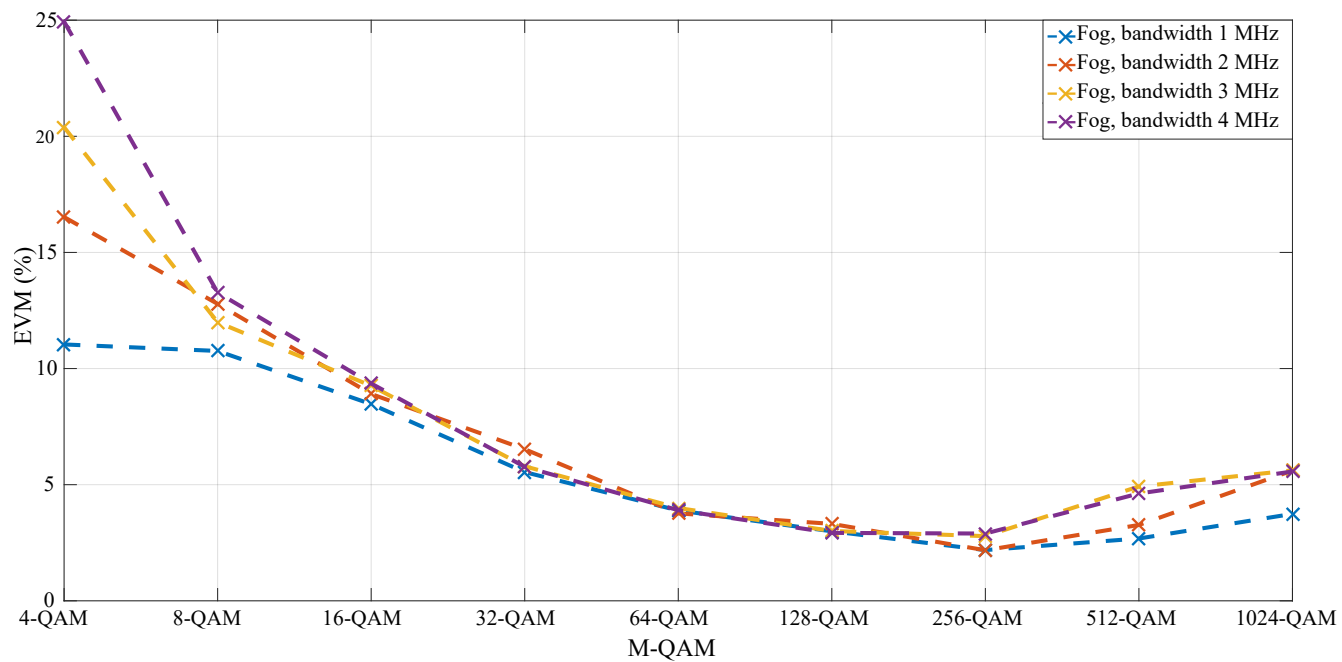

Figure 38. EVM/distance relationship for Octavia tail-light with different M-QAM and bandwidths -scenario 5-fog. 
From all the meteorological phenomena, fog had the greatest influence on visible light communication and will be the hardest to overcome. Figure 39 displays attenuation characteristics for different laser power levels. For example, at $1 \mathrm{~mW}$ output power, attenuation increased by $63 \mathrm{~dB}$ in comparison with reference values.

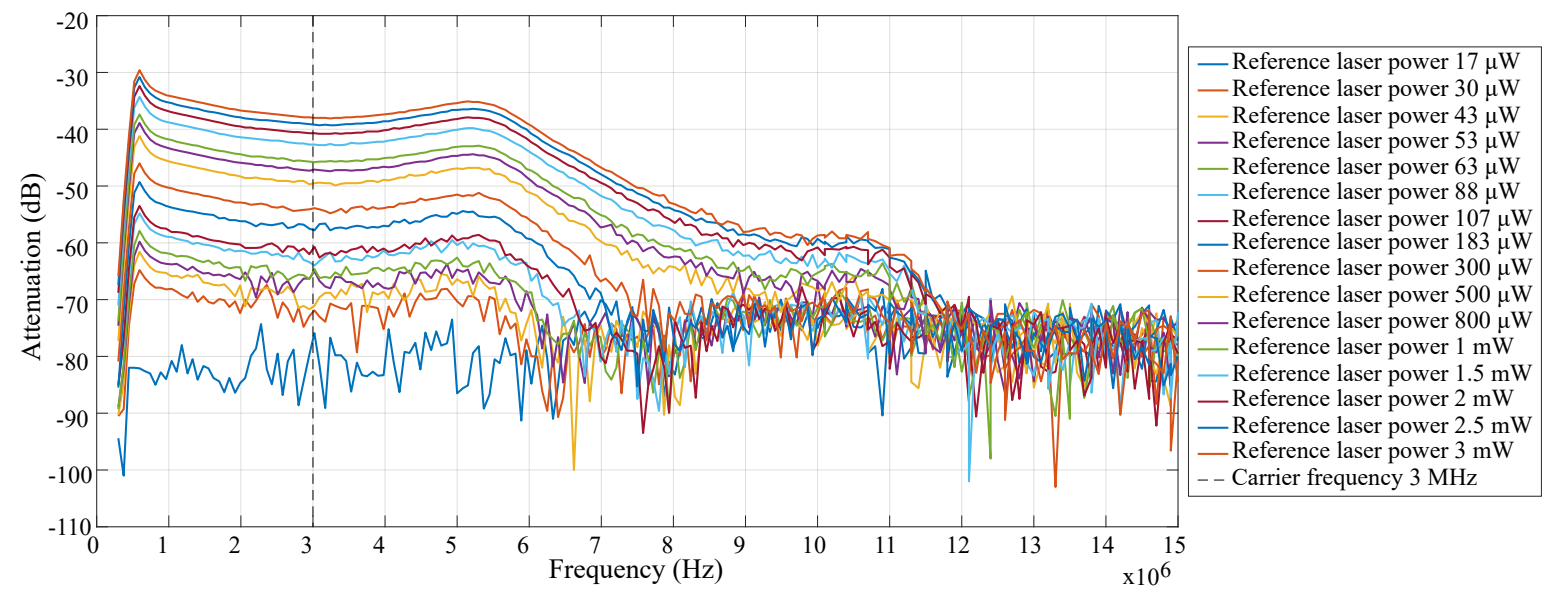

Figure 39. Attenuation characteristics of Octavia tail-light during fog dissipation -in scenario 5 - fog.

\section{Future Research and Discussion}

During testing we have encountered several shortcomings, we will try to overcome in the future. As our prototype is designed with the highest possible modularity in mind, we want to aim for better parts especially tailored for our needs. We have identified amplifier nonlinearity and photodetector as our biggest limitation. We were able to acquire two APD modules from Hamamatsu Photonics Japan, which will be tested, evaluated and possibly incorporated into our prototype $[103,104]$. There are also multiple companies we are currently in contact with to manufacture custom amplifiers such as Mini Circuits and Ophir RF.

Figures 6 and 13 show trend of increasing attenuation below $1 \mathrm{MHz}$ and above $5 \mathrm{MHz}$. It is caused either by insufficient optimization of inbuild pre or post equalizers or by an amplifier in combination with insufficient impedance matching. Nonlinearity at $1 \mathrm{MHz}$ to $5 \mathrm{MHz}$ did not cause any significant changes to transmission quality. However we are currently working on optimization and have ordered a number of specialized parts.

We would like to propose a new concept of software defined optics (SDO). SDO is a visible light communication system, in which the critical part of signal processing is implemented by software programmable circuits. As a result, a variety of software changes can be used to swiftly modify the communication system, such as used modulation, channel coding etc. The transmitter consists of $\mathrm{D} / \mathrm{A}$ converter and appropriate transmitter (LED or laser diode), which is modulated by a bias-tee. The receiver consists of a photodiode or camera and A/D converter.

The main advantage of our experiment was deployment of commercially available lights as transmitters. We avoided excessive modifications of original designs and tested them to their thresholds. However, we estimate, that modification of an Octavia tail-light LED cluster might increase effective maximal communication distance by $20 \%$, as original LED matrixes tend to be of lower quality.

Implementation of adaptive modulation and/or channel width would allow our setup to dynamically react to different conditions. We have also estimated that channel equalization would improve whole prototype significantly. Channel equalization implementation will be a topic of our immediate research, which will follow this paper shortly.

Next revision of our software will replace simpler QAM with full-fledged OFDM, which will also significantly improve our prototype. The next generation of our LabVIEW SDR VLC implementation is currently under development and will be a topic of further papers. 
Another advantage of our prototype is its software based on virtual instrumentation. LabVIEW SDR offers us a reliable and highly modular platform, which we can easily modify, adjust or move. Whole software was frequently moved between stationary desktop computer and powerful laptop, so we were able to test it in different labs with custom equipment, such as special box mentioned earlier. Main advantage lays in LabVIEW modularity. We can implement multiple functions very fast, such as addition of channel coding or equalization, which is a huge advantage in debug phase. The final implementation of our prototype will be minimalized and optimized. We estimate, that third generation of our software (second generation of OFDM) will run natively on FPGA.

Each measurements/tests were carried out multiple times and mainly independently. Each scenario was specially designed to represent the most pressing problems in VLC. Variable natural conditions and their compensation are a topic for multiple teams and their research $[6,9,37,105]$. As fog is the most concerning problem, several teams tried to compensate its impact $[47,106,107]$. A sandstorm, which was not tested in our paper, is considered as another concerning topic, however according to simulations, its characteristics is very similar to fog and rain [108].

We have also acquired a number of blue-light filters from Thorlabs. According to some papers, a system which uses these filters will have wider useable bandwidth but might suffer from shorter communication distance. Analysis of these parameters will be a topic of further research. As mentioned earlier, our Octavia taillight setup used plano-convex lens, which were already available at our university. We have also acquired another set of plano-convex and Fresnel lens which will be also a topic of further research.

Setup with indoor ceiling light could be enhanced with VLC positioning system, as there are a number of proposed implementations [109]. However primary purpose is data transmissions, so positioning would be only a supplementary function, which should not interfere with primary purpose or limit measured parameters. Some teams even reached up to $95 \%$ accuracy in their experiments. OFDM, or more specifically OFDMA can be used for data transmissions as well as positioning. Positioning methods are usually based on trilateration model, which needs at least three transmitters with known location. However, we have used only one ceiling light for prototyping, so positioning would not be possible. This area will be a topic of further research [110-114].

In case of VLC, most teams are mainly focused on achieving longer communication distances or higher transmit speeds. Security was pushed sideways in favor of other areas. However we agree with colleagues, that non-line-of-sight (NLoS) or even line-of-sight (LoS) eavesdropping is possible without sturdy security, which is not covered enough in IEEE standardization. Possible NLoS eavesdropping will be a topic for further research, as we are just entering this area [115].

Many teams tend to use their own LED matrixes or custom designed lights. However, that is concerning, as quality of deployed LEDs in commercially available products tend to vary significantly. Manufacturers often use lower quality LEDs, because even a small difference in price will make a huge impact in higher quantities. That's why we split our research into two branches. We begun our research on commercially available lights, as they are "target hardware". However we are also running a number of test on multiple LEDs of different qualities, and are looking for best price/performance ratio. This area will be also a topic of further research [7,79-82].

Technical University of Ostrava has its own newly developed testing polygon called "BroadbandLIGHT". BroadbandLIGHT is situated next to faculty of electrical engineering and computer science. It consists of 20 lamp posts and central management located in laboratory EB418 (see Figure 40). The whole system is prepared for future implementation of VLC technology. It is a unique polygon that is oriented at potential customers, demonstrations of functionality or long-term measurements. It is a next step for incorporation of smart technologies (smart city, IoT, Industry 4.0) into lighting and can be used for either indoor or outdoor setups. Detailed description and possible implementation will be discussed in further papers.

A new kind of hybrid system is currently in development by our team. It is based on powerline, which will be connected directly to ceiling light. The return channel is based on power efficient 
Bluetooth technology. It Is estimated that whole system should be much more energy efficient. It is based on the premise that most of the users download much more than they upload, which will result in lower battery drain.
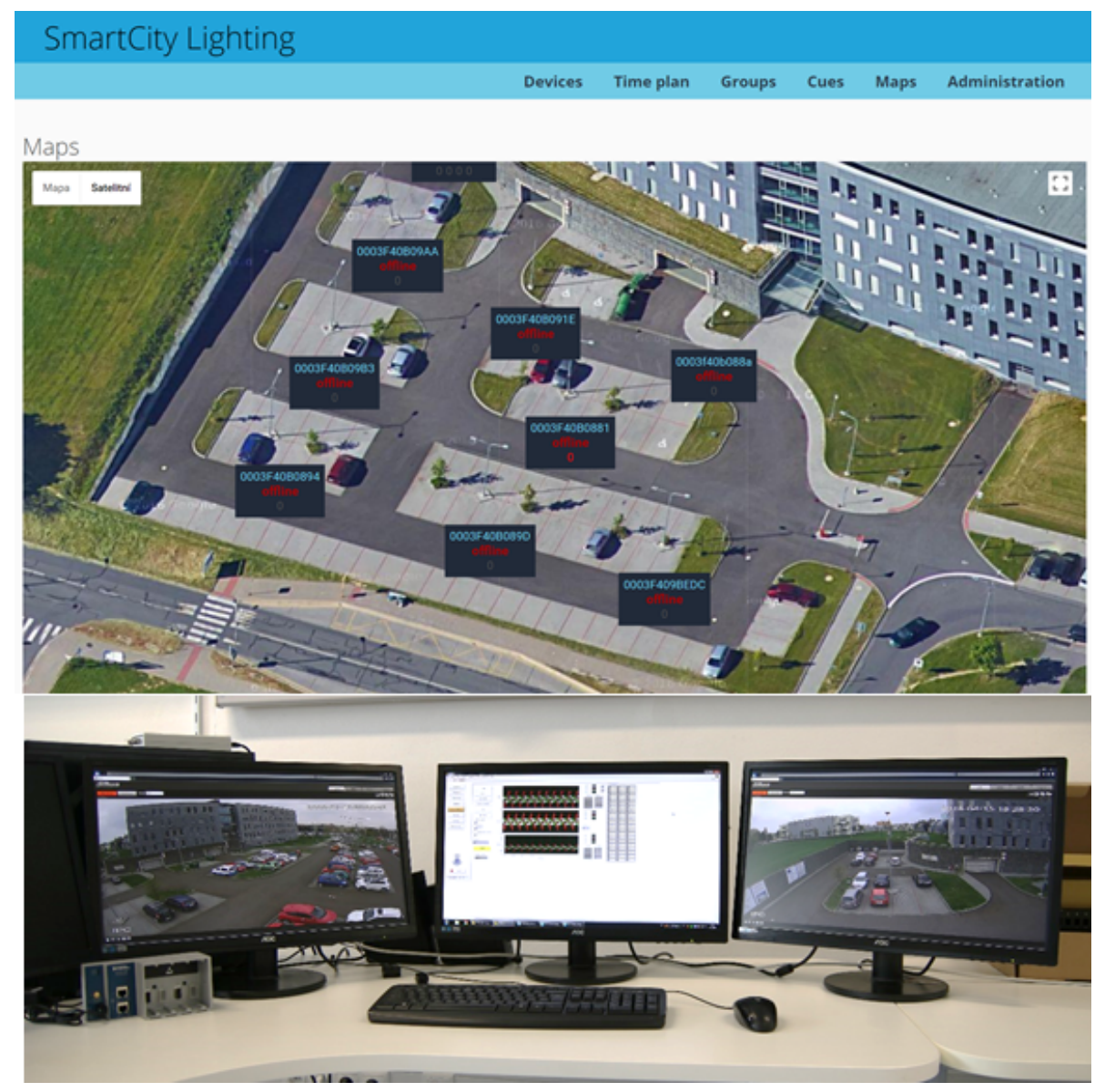

Figure 40. BroadbandLIGHT testing polygon implementation and management center.

Table 5 summarizes multiple tests with different configurations, including ours. We have included information about modulation, detector, maximal reachable transmit speed and even maximal reachable distance.

Next version of our prototype will feature advanced signal processing methods, which we already investigated multiple times in different areas [116-121]. 
Table 5. Comparison of different VLC experiments.

\begin{tabular}{|c|c|c|c|c|c|c|}
\hline Year & Main Author & Source & Distance & Detector & Modulation Type & Transmit Speed \\
\hline 2016 & Wen-Hsuan Shen [22] & $\begin{array}{l}\text { Tail-light } 1157 \\
(12 \mathrm{~V} \text {, red LED) }\end{array}$ & $45 \mathrm{~m}$ & $\begin{array}{l}\text { Photodiode Thorlabs } \\
\text { PDA100A } \\
(10 \mathrm{~mm} \times 10 \mathrm{~mm})\end{array}$ & PWM (OFDM) & 45-55 Mbps \\
\hline 2016 & Yuki Goto [30] & $\begin{array}{l}\text { Red LED matrix } \\
(4 \times 5 ; 0.72 \mathrm{~V}, 14.5 \mathrm{MHz})\end{array}$ & $1.5 \mathrm{~m}$ & $\begin{array}{l}\text { OCI camera } \\
\text { (Focal distance } \\
\text { of the lens } 50 \mathrm{~mm} \text { ) }\end{array}$ & 4-256 QAM (OFDM) & $\begin{array}{l}45 \text { Mbps } \\
50 \text { Mbps } \\
55 \text { Mbps }\end{array}$ \\
\hline 2014 & Isamu Takai [122] & $\begin{array}{l}\text { Red LED matrix } \\
(10 \times 10 ; 4 \mathrm{~W}, 55 \mathrm{MHz})\end{array}$ & $7.78 \mathrm{~m}$ & $\begin{array}{l}\text { High-speed camera } \\
\text { (Focal distance } \\
\text { of the lens } 12.5 \mathrm{~mm} \text { ) }\end{array}$ & $\begin{array}{l}\text { Pulse Width } \\
\text { modulation (PWM) }\end{array}$ & $10 \mathrm{Mpbs}$ \\
\hline 2014 & Takaya Yamazato [122] & $\begin{array}{l}\text { Red LED matrix } \\
(32 \times 32)\end{array}$ & $45 \mathrm{~m}$ & $\begin{array}{l}\text { High-speed camera } \\
\text { (CMOS sensor) }\end{array}$ & $\begin{array}{l}\text { Pulse Width } \\
\text { modulation (PWM) }\end{array}$ & $10 \mathrm{Mpbs}$ \\
\hline 2016 & Yoshihito Imai [123] & $\begin{array}{l}\text { Red LED } \\
\text { (OS5RKA5B61P) }\end{array}$ & $1-8 \mathrm{~m}$ & $\begin{array}{l}\text { High-speed camera } \\
\text { XCG-V60E, SONY } \\
\text { (Focal distance } \\
\text { of the lens } 8-48 \mathrm{~mm} \text { ) }\end{array}$ & $\begin{array}{l}\text { Pulse Width } \\
\text { modulation (PWM) }\end{array}$ & 84 bps \\
\hline 2017 & Takaya Yamazato [124] & $\begin{array}{l}\text { Red LED matrix } \\
(32 \times 32)\end{array}$ & $30-70 \mathrm{~m}$ & $\begin{array}{l}\text { High-speed image } \\
\text { sensor and OCI sensor }\end{array}$ & $\begin{array}{l}\text { Pulse Width } \\
\text { modulation (PWM) }\end{array}$ & $55 \mathrm{Mbps}$ \\
\hline 2019 & Radek Martinek & $\begin{array}{l}\text { Phillips Fortimo } \\
\text { DLM } 30044 \text { W/840 Gen3 }\end{array}$ & $3.25 \mathrm{~m}$ from center & Thorlabs PDA-36A & QAM modulation & $2 \mathrm{Mbps}$ \\
\hline 2019 & Radek Martinek & $\begin{array}{l}\text { Skoda Octavila } \\
\text { Tail-light }\end{array}$ & $5.5 \mathrm{~m}$ & Thorlabs PDA-36A & QAM modulation & $28 \mathrm{Mbps}$ \\
\hline
\end{tabular}




\section{Conclusions}

In this paper, we have presented results of our ongoing research. Our VLC prototype based on NI LabVIEW SDR and commercially available lights is introduced. First part of our experiment was carried out on Phillips indoor ceiling light. We have analyzed maximal possible transmit speeds at different distances from center, located directly below transmitter. The maximal reachable distance was $325 \mathrm{~m}$, when using 4-QAM and $1 \mathrm{MHz}$ bandwidth. Transmit speed was at least $2 \mathrm{Mbps}$. With wider channels and higher modulations (8-QAM to 256-QAM), maximal reachable distance decreased rapidly.

The second part was based on Octavia tail-light, which was tested under different natural conditions. A maximal measuring distance was constant $550 \mathrm{~cm}$. A special box was inserted between transmitter (tail-light) and receiver (photodetector), which simulated different conditions such as: thermal turbulence, rain and fog. A number of figures with real measured data was presented and commented accordingly. We have also identified weak spots, which will be adjusted and possibly researched in future publications. From measured data, fog has the greatest impact on communication, as it caused. On the other side, thermal turbulence had the lowest impact. The highest reachable transmit speed was $28 \mathrm{Mbps}$ for combination of 256-QAM and $4 \mathrm{MHz}$, which was reachable only in the empty box.

Weak spots were identified and thoroughly discussed. A number of possible upgrades were mentioned, focusing on custom parts, which will significantly improve whole setup.

Author Contributions: Conceptualization, R.M. and L.D.; Methodology, R.M.; Software, L.D. and R.M.; Validation, R.M., L.D. and R.J.; Formal Analysis, R.M. and L.D.; Investigation, R.M. and R.J.; Resources, R.M.; Data Curation, L.D.; Writing-Original Draft Preparation, L.D.; Writing-Review \& Editing, R.M. and R.J.; Visualization, R.J.; Supervision, R.M.; Project Administration, R.M.; Funding Acquisition, R.M.

Funding: This article was supported by the Ministry of Education of the Czech Republic (Project No. SP2019/85). This work was supported by the European Regional Development Fund in the Research Centre of Advanced Mechatronic Systems project, project number CZ.02.1.01/0.0/0.0/16_019/0000867 within the Operational Programme Research, Development and Education. This work was supported by the European Regional Development Fund in A Research Platform focused on Industry 4.0 and Robotics in Ostrava project, CZ.02.1.01/0.0/0.0/17_049/0008425 within the Operational Programme Research, Development and Education.

Conflicts of Interest: The authors declare no conflicts of interest.

\section{References}

1. Rajagopal, S.; Roberts, R. D.; Lim, S. K. IEEE 802.15. 7 visible light communication: Modulation schemes and dimming support. IEEE Commun. Mag. 2012, 50, 72-82. [PubMed] [CrossRef]

2. Le Minh, H.; O’Brien, D.; Faulkner, G.; Zeng, L.; Lee, K.; Jung, D.; Oh, T.; Won, E.T. 100-Mb/s NRZ visible light communications using a postequalized white LED. IEEE Photonics Technol. Lett. 2009, 21, 1063-1065. [PubMed] [CrossRef]

3. Biton, C.; Arnon, S. Improved multiple access resource allocation in visible light communication systems. Opt. Commun. 2018, 424, 98-102. [PubMed] [CrossRef]

4. Cailean, A.M.; Dimian, M. Current challenges for visible light communications usage in vehicle applications: A survey. IEEE Commun. Surveys Tutor. 2017, 19, 2681-2703. [PubMed] [CrossRef]

5. Bekhrad, P.; Leitgeb, E.; Ivanov, H. Benefits of visible light communication in car-to-car communication. In Proceedings of the of the Fiber Lasers and Glass Photonics: Materials through Applications, Swansea, UK, 22-26 April 2018; Volume 10683, p. 106833A. [CrossRef] [CrossRef]

6. Singh, G.; Srivastava, A.; Bohara, V.A. On Feasibility of VLC Based Car-to-Car Communication Under Solar Irradiance and Fog Conditions. In Proceedings of the 1st International Workshop on Communication and Computing in Connected Vehicles and Platooning, New Delhi, India, 29 October 2018; pp. 1-7. [PubMed] [CrossRef] 
7. Matus, V.; Maturana, N.; Azurdia-Meza, C.A.; Montejo-Sanchez, S.; Rojas, J. Hardware design of a prototyping platform for vehicular VLC using SDR and exploiting vehicles CAN bus. In Proceedings of the of the 2017 First South American Colloquium on Visible Light Communications (SACVLC), Santiago, Chile, 13 November 2017; pp. 1-4. [PubMed]

8. Luo, P.; Ghassemlooy, Z.; Le Minh, H.; Bentley, E.; Burton, A.; Tang, X. Fundamental analysis of a car to car visible light communication system. In Proceedings of the of the 2014 9th International Symposium on Communication Systems, Networks \& Digital Sign (CSNDSP), Manchester, UK, 23-25 July 2014; pp. 1011-1016. [PubMed] [CrossRef]

9. Kim, J.Y.; Park, B.S.; Choi, H.S.; Kim, S.E.; Moon, I.; Lee, C.G. Effect of interferences on indoor visible light car-to-car communication systems. In Proceedings of the Optical Modelling and Design IV, Brussels, Belgium, 3-7 April 2016; Volume 9889, p. 98891U. [CrossRef] [CrossRef]

10. Arnon, S. Optimised optical wireless car-to-traffic-light communication. Trans. Emerg. Telecommun. Technol. 2014, 25, 660-665. [PubMed] [CrossRef]

11. Jeong, J.; Lee, C.G.; Moon, I.; Kang, M.; Shin, S.; Kim, S. Receiver angle control in an infrastructure-to-car visible light communication link. In Proceedings of the 2016 IEEE Region 10 Conference (TENCON), Marina Bay Sands, Singapore, 22-25 November 2016; pp. 1957-1960. [PubMed] [CrossRef]

12. Deng, P.; Kavehrad, M. Real-time software-defined single-carrier QAM MIMO visible light communication system. In Proceedings of the 2016 Integrated Communications Navigation and Surveillance (ICNS), Herndon, VA, USA, 19-21 April 2016; pp. 5A3-1-5A3-11. [PubMed] [CrossRef]

13. Tsonev, D.; Videv, S.; Haas, H. Light fidelity (Li-Fi): Towards all-optical networking. In Proceedings of the Broadband Access Communication Technologies VIII, San Francisco, CA, USA, 1-6 February 2014; p. 900702. [CrossRef] [CrossRef]

14. Saini, H. Li-Fi (Light Fidelity)-The future technology In Wireless communication. J. Comput. Appl. 2016, 7, 13-15. [PubMed]

15. Bao, X.; Yu, G.; Dai, J.; Zhu, X. Li-Fi: Light fidelity-a survey. Wireless Netw. 2015, 21, 1879-1889. [CrossRef] [CrossRef]

16. Haas, H.; Yin, L.; Wang, Y.; Chen, C. What is lifi? J. Lightwave Technol. 2016, 34, 1533-1544. [CrossRef] [CrossRef]

17. Sharma, R.R.; Sanganal, A. Li-Fi Technology: Transmission of data through light. Int. J. Comput. Technol. Appl. 2014, 5, 150. [PubMed]

18. Nivrutti, D. V.; Nimbalkar, R. R. Light-Fidelity: A Reconnaissance of Future Technology. Int. J. Adv. Res. Comput. Sci. Softw. Eng. 2013, 3. [PubMed]

19. Sarkar, A.; Agarwal, S.; Nath, A. Li-fi technology: Data transmission through visible light. Int. J. Adv. Res. Comput. Sci. Manag. Stud. 2015, 3. [PubMed]

20. Haas, H. LiFi: Conceptions, misconceptions and opportunities. In Proceedings of the 2016 IEEE Photonics Conference (IPC), Waikoloa, HI, USA, 2-6 October 2016; pp. 680-681. [PubMed] [CrossRef]

21. Jaiswal, N.S.; Chopade, P.S. Review of Li-Fi technology: New future technology-light bulb to access the internet! Int. J. Sci. Eng. Res. 2013, 4, 36-40.

22. Shen, W.H.; Tsai, H.M. Testing vehicle-to-vehicle visible light communications in real-world driving scenarios. In Proceedings of the 2017 IEEE Vehicular Networking Conference (VNC), Torino, Italy, 27-29 November 2017; pp. 187-194. [PubMed] [CrossRef]

23. Stewart, R.W.; Barlee, K.W.; Atkinson, D.S.; Crockett, L.H. Software Defined Radio Using MATLAB E Simulink and the RTL-SDR; Strathclyde Academic Media: Glasgow, UK, 2015.

24. Al Wohaishi, M.; Zidek, J.; Martinek, R. Analysis of M state digitally modulated signals in communication systems based on SDR concept. In Proceedings of the 6th IEEE International Conference on Intelligent Data Acquisition and Advanced Computing Systems, Prague, Czech Republic, 15-17 September 2011; pp. 171-175. [PubMed] [CrossRef]

25. Rahaim, M.; Miravakili, A.; Borogovac, T.; Little, T. D. C.; Joyner, V. Demonstration of a software defined visible light communication system. In the 17th Annual International Conference on Mobile Computing and Networking, Mobicom2011, Las Vegas, NV, USA, 19-23 September 2011. [PubMed]

26. Hussain, W.; Ugurdag, H.F.; Uysal, M. Software defined VLC system: Implementation and performance evaluation. In Proceedings of the 2015 4th International Workshop on Optical Wireless Communications (IWOW), Istanbul, Turkey, 7-8 September 2015; pp. 117-121. [PubMed] [CrossRef] 
27. Philips. Philips Fortimo LED Downlight Module System. Phillips Fortimo DLM 30044 W/840 Gen3 Datasheet. Available online: http:/ / media.futureelectronics.com/semiconductors/lighting-solutions/ledlight-modules/fortimo_dlm_twist.pdf?m=Q3SoAq.pdf (accessed on 28 February 2019). [PubMed]

28. Thorlabs. PDA36A Operating Manual-Switchable Gain, Amplified Silicon Detector. PDA36A-EC Datasheet. Avaialble online: http://physics-astronomy-manuals.wwu.edu/Thorlabs\%20PDA36A\% 20Detector\%20Manual.pdf (access on 28 February 2019) [PubMed]

29. Masini, B.; Bazzi, A.; Zanella, A. A survey on the roadmap to mandate on board connectivity and enable V2V-based vehicular sensor networks. Sensors 2018, 18, 2207. [CrossRef] [CrossRef] [PubMed]

30. Goto, Y.; Takai, I.; Yamazato, T.; Okada, H.; Fujii, T.; Kawahito, S.; Shintaro, A.; Tomohiro Yendo, T.; Kamakura, K. A new automotive VLC system using optical communication image sensor. IEEE Photonics J. 2016, 8, 1-17. [PubMed] [CrossRef]

31. Raza, N.; Jabbar, S.; Han, J.; Han, K. Social vehicle-to-everything (V2X) communication model for intelligent transportation systems based on 5G scenario. In Proceedings of the 2nd International Conference on Future Networks and Distributed Systems, Amman, Jordan, 26-27 June 2018; p. 54. [PubMed] [CrossRef]

32. Kinoshita, M.; Yamazato, T.; Okada, H.; Fujii, T.; Arai, S.; Yendo, T.; Kamakura, K. Motion modeling of mobile transmitter for image sensor based I2V-VLC, V2I-VLC, and V2V-VLC. In Proceedings of the 2014 IEEE Globecom Workshops (GC Wkshps), Austin, TX, USA, 8-12 December 2014; pp. 450-455. [PubMed] [CrossRef]

33. Kim, B. W.; Jung, S.Y. Vehicle positioning scheme using V2V and V2I visible light communications. In Proceedings of the 2016 IEEE 83rd Vehicular Technology Conference (VTC Spring), Nanjing, China, 20 September 2015; pp. 1-5. [PubMed] [CrossRef]

34. Vaezi, M.; Ding, Z.; Poor, H.V. Multiple Access Techniques for 5G Wireless Networks and Beyond; Springer: Berlin, Germany, 2019. [PubMed]

35. Boban, M.; Kousaridas, A.; Manolakis, K.; Eichinger, J.; Xu, W. Connected roads of the future: Use cases, requirements, and design considerations for vehicle-to-everything communications. IEEE Veh. Technol. Mag. 2016, 13, 110-123. [PubMed] [CrossRef]

36. Cailean, A.M.; Cagneau, B.; Chassagne, L.; Popa, V.; Dimian, M. A survey on the usage of DSRC and VLC in communication-based vehicle safety applications. In Proceedings of the 2014 IEEE 21st Symposium on Communications and Vehicular Technology in the Benelux (SCVT), Delft, The Netherlands, 10 November 2014; pp. 69-74. [PubMed] [CrossRef]

37. Kim, Y.H.; Cahyadi, W.A.; Chung, Y.H. Experimental demonstration of LED-based vehicle to vehicle communication under atmospheric turbulence. In Proceedings of the 2015 International Conference on Information and Communication Technology Convergence (ICTC), Jeju Island, Korea, 18-30 October 2015; pp. 1143-1145. [PubMed] [CrossRef]

38. Campolo, C.; Molinaro, A.; Scopigno, R. From today's VANETs to tomorrow's planning and the bets for the day after. Veh. Commun. 2015, 2, 158-171. [CrossRef] [CrossRef]

39. Yamazato, T. Overview of visible light communications with emphasis on image sensor communications. In Proceedings of the 2017 23rd Asia-Pacific Conference on Communications (APCC), Perth, WA, Australia, 11-13 December 2017; pp. 1-6. [PubMed] [CrossRef]

40. Yamazato, T. Image Sensor Communications for future ITS. In Proceedings of the Signal Processing in Photonic Communications (pp. SpW2G-6). Optical Society of America, Zurich, Switzerland, 2-5 July 2018. [CrossRef] [CrossRef]

41. Tsado, Y.; Lund, D.; Gamage, K.A. Resilient communication for smart grid ubiquitous sensor network: State of the art and prospects for next generation. Comput. Commun. 2015, 71, 34-49. [CrossRef] [CrossRef]

42. Tareen, W.U.K.; Mekhilef, S.; Nakaoka, M. A transformerless reduced switch counts three-phase APF-assisted smart EV charger. In Proceedings of the 2017 IEEE Applied Power Electronics Conference and Exposition (APEC), Tampa, FL, USA, 26-30 March 2017; pp. 3307-3312. [PubMed] [CrossRef]

43. Roche, R.; Berthold, F.; Gao, F.; Wang, F.; Ravey, A.; Williamson, S. A model and strategy to improve smart home energy resilience during outages using vehicle-to-home. In Proceedings of the 2014 IEEE International Electric Vehicle Conference (IEVC), Florence, Italy, 17-19 December 2014; pp. 1-6. [PubMed] [CrossRef]

44. Turker, H.; Bacha, S. Optimal Minimization of Plug-in Electric Vehicle Charging Cost with Vehicle-to-Home and Vehicle-to-Grid concepts. IEEE Trans. Veh. Technol. 2018 67, 10281-10292. [PubMed] [CrossRef] 
45. Yamazato, T. V2X communications with an image sensor. J. Commun. Inf. Netw. 2017, 2, 65-74. [CrossRef] [CrossRef]

46. Mare, R.M.; Marte, C.L.; Cugnasca, C.E. Visible light communication applied to intelligent transport systems: An Overview. IEEE Latin Am.Trans. 2016, 14, 3199-3207. [PubMed] [CrossRef]

47. Kim, Y.H.; Cahyadi, W.A.; Chung, Y.H. Experimental demonstration of VLC-based vehicle-to-vehicle communications under fog conditions. IEEE Photonics J. 2015, 7, 1-9. [PubMed] [CrossRef]

48. Kinoshita, M.; Yamazato, T.; Okada, H.; Fujii, T.; Arai, S.; Yendo, T.; Kamakura, K. Channel fluctuation measurement for image sensor based I2v-VLC, V2i-VLC, and V2v-VLC. In Proceedings of the 2014 IEEE Asia Pacific Conference on Circuits and Systems (APCCAS), Okinawa, Japan, 17-20 November 2014; pp. 332-335. [PubMed] [CrossRef]

49. Arena, F.; Pau, G. An Overview of Vehicular Communications. Future Internet 2019, 11, 27. [CrossRef] [CrossRef]

50. Goldman-Shenhar, C.V.; Friedland, Y.S.; Riess, E.; Philosof, T.; Tsimhoni, O. Vehicle-to-PedestrianCommunication Systems and Methods for Using the Same. U.S. Patent No. 9,881,503, U.S. Patent 30 January 2018.

51. Viriyasitavat, W.; Boban, M.; Tsai, H. M.; Vasilakos, A. Vehicular communications: Survey and challenges of channel and propagation models. IEEE Veh. Technol. Mag. 2015, 10, 55-66. [PubMed] [CrossRef]

52. Wang, Y.; Sheikh, O.; Hu, B.; Chu, C.C.; Gadh, R. Integration of V2H/V2G hybrid system for demand response in distribution network. In Proceedings of the 2014 IEEE International Conference on Smart Grid Communications (SmartGridComm), Venice, Italy, 3-6 November 2014; pp. 812-817. [PubMed] [CrossRef]

53. Zhao, L.; Aravinthan, V. Strategies of residential peak shaving with integration of demand response and V2H. In Proceedings of the 2013 IEEE PES Asia-Pacific Power and Energy Engineering Conference (APPEEC), Kowloon, Hong Kong, 11 December 2013; pp. 1-5. [PubMed] [CrossRef]

54. Guille, C.; Gross, G. A conceptual framework for the vehicle-to-grid (V2G) implementation. Energy Policy 2009, 37, 4379-4390. [CrossRef] [CrossRef]

55. Ota, Y.; Taniguchi, H.; Nakajima, T.; Liyanage, K.M.; Baba, J.; Yokoyama, A. Autonomous distributed V2G (vehicle-to-grid) satisfying scheduled charging. IEEE Trans. Smart Grid. 2012, 3, 559-564. [PubMed] [CrossRef]

56. Alam, M. Vehicle-to-Everything (V2X) Technology Will Be a Literal Life Saver But What Is It?, 2016. Available online: http:/ / eecatalog.com/automotive/2016/05/19/vehicle-to-everything-v2x-technology-will-be-aliteral-life-saver-but-what-is-it/ (access on: 28 February 2019) [PubMed]

57. Ng, X.W.; Chung, W.Y. VLC-based medical healthcare information system. Biomed. Eng. Appl. Basis Commun. 2012, 24, 155-163. [CrossRef] [CrossRef]

58. Ding, W.; Yang, F.; Yang, H.; Wang, J.; Wang, X.; Zhang, X.; Song, J. A hybrid power line and visible light communication system for indoor hospital applications. Comput. Ind. 2015, 68, 170-178. [CrossRef] [CrossRef]

59. An, J.; Chung, W.Y. A novel indoor healthcare with time hopping-based visible light communication. In Proceedings of the 2016 IEEE 3rd World Forum on Internet of Things (WF-IoT), Reston, VA, USA, 12-14 December 2016; pp. 19-23. [PubMed] [CrossRef]

60. Song, J.; Ding, W.; Yang, F.; Yang, H.; Wang, J.; Wang, X.; Zhang, X. Indoor hospital communication systems: An integrated solution based on power line and visible light communication. In Proceedings of the 2014 IEEE Faible Tension Faible Consommation, Monaco, Monaco, 4-6 May 2014; pp. 1-6. [PubMed] [CrossRef]

61. Tagliaferri, D.; Capsoni, C. SNIR predictions for on-aircraft VLC systems. In Proceedings of the 2016 International Conference on Broadband Communications for Next Generation Networks and Multimedia Applications (CoBCom), Graz, Austria, 14-16 September 2016 ; pp. 1-7. [PubMed] [CrossRef]

62. Png, L.C.; Lim, S.X.; Rajamohan, A.; Chan, B.W.; Hazman, F.A. Designs of VLC transceiver circuits for reading light transmission of high-quality audio signals on commercial airliners. In Proceedings of the 2014 IEEE International Conference on Consumer Electronics-Taiwan, Taipei, Taiwan, 26-28 May 2014; pp. 97-98. [PubMed] [CrossRef]

63. Burchardt, H.; Serafimovski, N.; Tsonev, D.; Videv, S.; Haas, H. VLC: Beyond point-to-point communication. IEEE Commun. Mag. 2014, 52, 98-105. [PubMed] [CrossRef]

64. Kumar, A.; Mihovska, A.; Kyriazakos, S.; Prasad, R. Visible light communications (VLC) for ambient assisted living. Wirel. Pers. Commun. 2014, 78, 1699-1717. [CrossRef] [CrossRef] 
65. Varghese, A.; Tandur, D. Wireless requirements and challenges in Industry 4.0. In Proceedings of the 2014 International Conference on Contemporary Computing and Informatics (IC3I), Mysore, India, 27-29 November 2014; pp. 634-638. [PubMed] [CrossRef]

66. Cwikla, G.; Foit, K. Problems of integration of a manufacturing system with the business area of a company on the example of the Integrated Manufacturing Systems Laboratory. In Proceedings of the MATEC Web of Conferences, Brasov, Romania, 3-4 November 2016; Volume 94, p. 06004. [CrossRef] [CrossRef]

67. Cerruela Garcia, G.; Luque Ruiz, I.; Gomez-Nieto, M. State of the art, trends and future of bluetooth low energy, near field communication and visible light communication in the development of smart cities. Sensors 2016, 16, 1968. [CrossRef] [CrossRef]

68. Brena, R.F.; Garcia-Vazquez, J.P.; Galvan-Tejada, C.E.; Munoz-Rodriguez, D.; Vargas-Rosales, C.; Fangmeyer, J. Evolution of indoor positioning technologies: A survey. J. Sens. 2017. [CrossRef] [CrossRef]

69. Memedi, A.; Tsai, H.M.; Dressler, F. Impact of realistic light radiation pattern on vehicular visible light communication. In Proceedings of the GLOBECOM 2017-2017 IEEE Global Communications Conference, Singapore, Singapore, 4-8 December 2017; pp. 1-6. [PubMed] [CrossRef]

70. Chen, L.; Wang, W.; Zhang, C. Coalition formation for interference management in visible light communication networks. IEEE Trans. Veh. Technol. 2017, 66, 7278-7285. [PubMed] [CrossRef]

71. Varanva, D.J.; Prasad, K.M. LED to LED communication with WDM concept for flash light of Mobile phones. Edit. Preface 2013, 4. [PubMed] [CrossRef]

72. Cui, Z.; Yue, P.; Ji, Y. Study of cooperative diversity scheme based on visible light communication in VANETs. In Proceedings of the 2016 International Conference on Computer, Information and Telecommunication Systems (CITS), Kunming, China, 6-8 July 2016; pp. 1-5. [PubMed] [CrossRef]

73. Mare, R.M.; Cugnasca, C.E.; Marte, C.L.; Gentile, G. Intelligent transport systems and visible light communication applications: An overview. In Proceedings of the 2016 IEEE 19th International Conference on Intelligent Transportation Systems (ITSC), Rio de Janeiro, Brazil, 1-4 November 2016; pp. 2101-2106. [PubMed] [CrossRef]

74. Alam, K.M.; Saini, M.; El Saddik, A. Toward social internet of vehicles: Concept, architecture, and applications. IEEE Access. 2015, 3, 343-357. [PubMed] [CrossRef]

75. Nitti, M.; Girau, R.; Floris, A.; Atzori, L. On adding the social dimension to the internet of vehicles: Friendship and middleware. In Proceedings of the 2014 IEEE international black sea conference on communications and networking (BlackSeaCom), Odessa, Ukraine, 27-30 May 2014; pp. 134-138. [PubMed] [CrossRef]

76. Maglaras, L.; Al-Bayatti, A.; He, Y.; Wagner, I.; Janicke, H. Social internet of vehicles for smart cities. J. Sens. Actuator Netw. 2016, 5, 3. [CrossRef] [CrossRef]

77. Yoo, J.H.; Jang, J.S.; Kwon, J. K.; Kim, H.C.; Song, D.W.; Jung, S.Y. Demonstration of vehicular visible light communication based on LED headlamp. Int. J. Automot. Technol., 2016, 17, 347-352. [CrossRef] [CrossRef]

78. Uysal, M.; Ghassemlooy, Z.; Bekkali, A.; Kadri, A.; Menouar, H. Visible light communication for vehicular networking: Performance study of a V2V system using a measured headlamp beam pattern model. IEEE Veh. Technol. Mag. 2015, 10, 45-53. [CrossRef] [CrossRef]

79. Turan, B.; Narmanlioglu, O.; Ergen, S.C.; Uysal, M. Physical layer implementation of standard compliant vehicular VLC. In Proceedings of the 2016 IEEE 84th Vehicular Technology Conference (VTC-Fall), Montreal, Canada, 8-21 September 2016 ; pp. 1-5. [PubMed] [CrossRef]

80. Costanzo, A.; Loscri, V.; Costanzo, S. Software Defined Platforms for Visible Light Communication: State of Art and New Possibilities. IEEE Commun. Soc. Multim. Commun. Tech. Committee 2017, 12, 14-18. [PubMed]

81. Bhunia, S.; Sengupta, S. Implementation of interface agility for duplex dynamic spectrum access radio using USRP. In Proceedings of the MILCOM 2017-2017 IEEE Military Communications Conference (MILCOM), Maryland, USA, 23-25 October 2017; pp. 762-767. [PubMed] [CrossRef]

82. Baranda, J.; Henarejos, P.; Gavrincea, C.G. An SDR implementation of a visible light communication system based on the IEEE 802.15. 7 standard. In Proceedings of the ICT 2013, Litva, Czech Republic, 6-8 November 2013; pp. 1-5. [PubMed] [CrossRef]

83. Deng, P.; Kavehrad, M. Adaptive real-time software defined MIMO visible light communications using spatial multiplexing and spatial diversity. In Proceedings of the 2016 IEEE International Conference on Wireless for Space and Extreme Environments (WiSEE), Aachen, Germany, 26-29 September 2016; pp. 111-116. [PubMed] [CrossRef] 
84. Deng, P. Real-Time Software-Defined Adaptive MIMO Visible Light Communications. In Visible Light Communications; IntechOpen: London, UK, 2017. [PubMed] [CrossRef]

85. Tsonev, D.; Chun, H.; Rajbhandari, S.; McKendry, J.J.; Videv, S.; Gu, E.; Haji, M.; Watson, S.; Kelly, A.E.; Faulkner, G.; et al. Dawson, M.D. A 3-Gb/s Single-LED OFDM-Based Wireless VLC Link Using a Gallium Nitride $\mu$ LED. IEEE Photonics Technol. Lett. 2014, 26, 637-640. [PubMed] [CrossRef]

86. Bandara, K.; Niroopan, P.; Chung, Y.H. PAPR reduced OFDM visible light communication using exponential nonlinear companding. In Proceedings of the 2013 IEEE International Conference on Microwaves, Communications, Antennas and Electronic Systems (COMCAS 2013), Tel Aviv, Israel, 21-23 October 2013; pp. 1-5. [PubMed] [CrossRef]

87. Khalid, A.; Asif, H.M. NI cDAQ based software-defined radio for visible light communication system. In Proceedings of the 2017 2nd Workshop on Recent Trends in Telecommunications Research (RTTR), Palmerston North, New Zealand, 10 February 2017; pp. 1-5. [PubMed] [CrossRef]

88. Tsiropoulou, E.E.; Gialagkolidis, I.; Vamvakas, P.; Papavassiliou, S. Resource allocation in visible light communication networks: NOMA vs OFDMA transmission techniques. In Proceedings of the International Conference on Ad-Hoc Networks and Wireless, Lille, France, 4-6 July 2016; pp. 32-46. Springer, Cham, Switzerland. [CrossRef] [CrossRef]

89. Kizilirmak, R.C.; Rowell, C.R.; Uysal, M. Non-orthogonal multiple access (NOMA) for indoor visible light communications. In Proceedings of the 2015 4th International Workshop on Optical Wireless Communications (IWOW), Istanbul, Turkey, 7-8 September 2015; pp. 98-101. [PubMed] [CrossRef]

90. Yapici, Y.; Guvenc, I. Non-orthogonal multiple access for mobile VLC networks with random receiver orientation. arXiv 2018, arXiv:1801.04888. [PubMed]

91. Saito, Y.; Kishiyama, Y.; Benjebbour, A.; Nakamura, T.; Li, A.; Higuchi, K. Non-orthogonal multiple access (NOMA) for cellular future radio access. In Proceedings of the 2013 IEEE 77th vehicular technology conference (VTC Spring), Dresden, Germany, 2-5 June 2013; pp. 1-5. [PubMed] [CrossRef]

92. Lin, B.; Ye, W.; Tang, X.; Ghassemlooy, Z. Experimental demonstration of bidirectional NOMA-OFDMA visible light communications. Opt. Express. 2017, 25, 4348-4355. [CrossRef] [CrossRef]

93. Tsiropoulou, E.E.; Vamvakas, P.; Papavassiliou, S. Resource Allocation in Multi-tier Femtocell and Visible-Light Heterogeneous Wireless Networks. Resource Allocation in Next-Generation Broadband Wireless Access Networks. IGI Global: Hershey, PA, USA, 2017. [PubMed] [CrossRef]

94. Singhal, C., De, S. (Eds.) Resource Allocation in Next-Generation Broadband Wireless Access Networks; IGI Global: Hershey, PA, USA, 2017

95. National Instruments. Universal Software Radio Peripheral. NI USRP-2920/2921/2922 Datasheet. Available online: http:/ / www.ni.com/pdf/manuals/376358a.pdf (access on 28 February 2019). [PubMed]

96. Mini-Circuits. Coaxial Bias-Tee. ZX85-12G-S+ Datasheet. Available online: https://www.minicircuits.com/ pdfs /ZX85-12G-S+.pdf (access on: 28 February 2019). [PubMed]

97. Welch, T.B.; Shearman, S. Teaching software defined radio using the USRP and LabVIEW. In Proceedings of the 2012 IEEE International Conference on Acoustics, Speech and Signal Processing (ICASSP), Kyoto, Japan, 25-30 March 2012; pp. 2789-2792. [PubMed] [CrossRef]

98. Marriwala, N.; Sahu, O.P.; Vohra, A. LabVIEW based design implementation of M-PSK transceiver using multiple forward error correction coding technique for software defined radio applications. J. Electrical Electron. Eng. 2014, 2, 55-63. [PubMed] [CrossRef]

99. Haigh, P.A.; Burton, A.; Werfli, K.; Le Minh, H.; Bentley, E.; Chvojka, P.; Popoola, W.O.; Papakonstantinou, I.; Zvanovec, S. Zvanovec, S. A multi-CAP visible-light communications system with $4.85-\mathrm{b} / \mathrm{s} / \mathrm{Hz}$ spectral efficiency. IEEE J. Sel. Areas Commun. 2015, 33, 1771-1779. [PubMed] [CrossRef]

100. Urick, V.J.; Qiu, J.X.; Bucholtz, F. Wide-band QAM-over-fiber using phase modulation and interferometric demodulation. IEEE Photonics Technol. Lett. 2004, 16, 2374-2376. [PubMed] [CrossRef]

101. Schmogrow, R.; Nebendahl, B.; Winter, M.; Josten, A.; Hillerkuss, D.; Koenig, S.; Meyer, J.; Dreschmann, M.; Huebner, M.; Koos,C.; et al Becker, J. Error vector magnitude as a performance measure for advanced modulation formats. IEEE Photonics Technol. Lett. 2012, 24, 61-63. [PubMed] [CrossRef]

102. Alonso, D.E. Wireless Data Transmission for the Battery Management System of Electric and Hybrid Vehicles; KIT Scientific Publishing: Karlsruhe, Germany, 2017; Volume 15. [PubMed] 
103. Hamamatsu. Operates an APD with Single $5 \mathrm{v}$ Supply (Standard Type, Short-Wavelength Type). Singh2018702 Datasheet. Available online: https://www.hamamatsu.com/resources/pdf/ssd/ Singh2018702series_kacSingh201814e.pdf (accessed on 28 February 2019). [PubMed]

104. Hamamatsu. Detects Opcial Signals at $1 \mathrm{GHz}$, with High Sensitivity. Shen 2017658 Datasheet. Available online: https:/ / www.hamamatsu.com/resources/pdf/ssd/Shen2017658_kacLuo201423e.pdf (accessed on 28 February 2019). [PubMed]

105. Elamassie, M.; Karbalayghareh, M.; Miramirkhani, F.; Kizilirmak, R.C.; Uysal, M. Effect of fog and rain on the performance of vehicular visible light communications. In Proceedings of the 2018 IEEE 87th Vehicular Technology Conference (VTC Spring), Porto, Portugal, 3-6 June 2018; 1-6. [PubMed]

106. Hossain, F.; Afroze, Z. Eliminating the effect of fog attenuation on FSO link by multiple TX/RX system with travelling wave semiconductor optical amplifier. In Proceedings of the 2013 2nd International Conference on Advances in Electrical Engineering (ICAEE), Dhaka, Bangladesh, 19-21 December; pp. 267-272. [PubMed] [CrossRef]

107. Kim, I.I.; McArthur, B.; Korevaar, E.J. Comparison of laser beam propagation at $785 \mathrm{~nm}$ and $1550 \mathrm{~nm}$ in fog and haze for optical wireless communications. In Proceedings of the Optical Wireless Communications III, Boston, MA, USA, 6 February 2001; Volume 4214, pp. 26-38. [CrossRef] [CrossRef]

108. Ebrahim, K.J.; Al-Omary, A. Sandstorm Effect on Visible Light Communication. In Proceedings of the 2017 9th IEEE-GCC Conference and Exhibition (GCCCE), Manama, Bahrain, 8-11 May 2017; pp. 1-7. [PubMed] [CrossRef]

109. Luo, P.; Ghassemlooy, Z.; Le Minh, H.; Khalighi, A.; Zhang, X.; Zhang, M.; Yu, C. Experimental demonstration of an indoor visible light communication positioning system using dual-tone multi-frequency technique. In Proceedings of the 2014 3rd International Workshop in Optical Wireless Communications (IWOW), Funchal, Madeira Island, Portugal, 17 September 2014; pp. 55-59. [PubMed] [CrossRef]

110. Zhang, W.; Chowdhury, M.S.; Kavehrad, M. Asynchronous indoor positioning system based on visible light communications. Opt. Engineering 2014, 53, 045105. [CrossRef] [CrossRef]

111. Ganti, D.; Zhang, W.; Kavehrad, M. VLC-based indoor positioning system with tracking capability using Kalman and particle filters. In Proceedings of the 2014 IEEE International Conference on Consumer Electronics (ICCE), Las Vegas, NV, USA, 4-6 January 2014; pp. 476-477. [PubMed] [CrossRef]

112. Lin, B.; Tang, X.; Ghassemlooy, Z.; Lin, C.; Li, Y. Experimental demonstration of an indoor VLC positioning system based on OFDMA. IEEE Photonics J. 2017, 9, 1-9. [PubMed] [CrossRef]

113. Yamaguchi, S.; Mai, V.V.; Thang, T.C.; Pham, A.T. Design and performance evaluation of VLC indoor positioning system using optical orthogonal codes. In Proceedings of the 2014 IEEE Fifth International Conference on Communications and Electronics (ICCE), Danang, Vietnam, 30 July-1 August 2014; pp. 54-59. [PubMed] [CrossRef]

114. Huynh, P.; Yoo, M. VLC-based positioning system for an indoor environment using an image sensor and an accelerometer sensor. Sensors 2016, 16, 783. [CrossRef] [CrossRef]

115. Blinowski, G. Security issues in visible light communication systems. IFAC-PapersOnLine 2015, 48, $234-239$. [CrossRef] [CrossRef]

116. Martinek, R.; Zidek, J. The real implementation of ANFIS channel equalizer on the system of software-defined radio. IETE J. Res. 2014, 60, 183-193. [CrossRef] [CrossRef]

117. Martinek, R.; Zidek, J. The real implementation of NLMS channel equalizer into the system of software defined radio. Adv. Electr. Electron. Eng. 2012, 10, 330-336. [PubMed] [CrossRef]

118. Martinek, R.; Konecny, J.; Koudelka, P.; Zidek, J.; Nazeran, H. Adaptive optimization of control parameters for feed-forward software defined equalization. Wirel. Pers. Commun. 2017, 95, 4001-4011. [CrossRef] [CrossRef]

119. Martinek, R.; Vanus, J.; Bilik, P.; Al-Wohaishi, M.; Zidek, J.; Wen, H. The implementation of equalization algorithms for real transmission channels. In Proceedings of the 2016 IEEE International Instrumentation and Measurement Technology Conference Proceedings, Taipei, Taiwan, 23-26 May 2016; pp. 1-6. [PubMed] [CrossRef]

120. Martinek, R.; Vanus, J.; Kelnar, M.; Bilik, P.; Zidek, J. Application of recursive least square algorithm to adaptive channel equalization. In Proceedings of the XXI IMEKO World Congress Measurement in Research and Industry, Prague, Czech Republic, 30 August-4 September 2015; IMEKO-International Measurement Federation Secretariat: Budapest, Hungary, 2015; pp. 1-4. [PubMed] 
121. Martinek, R.; Razera, G.; Kahankova, R.; Zidek, J. Optimization of the training symbols for minimum mean square error equalizer. In Proceedings of the International Afro-European Conference for Industrial Advancement, Marrakesh, Morocco, 21-23 November 2016; Springer: Cham, Switzerland, 2016; pp. $272-287$. [CrossRef] [CrossRef]

122. Yamazato, T.; Takai, I.; Okada, H.; Fujii, T.; Yendo, T.; Arai, S.; Andoh, M.; Harada, T.; Yasutomi, K.; Kagawa, K.; et al. Kawahito, S. Image-sensor-based visible light communication for automotive applications. IEEE Commun. Mag. 2014, 52, 88-97. [PubMed] [CrossRef]

123. Imai, Y.; Ebihara, T.; Mizutani, K.; Wakatsuki, N. Performance evaluation of high-speed visible light communication combining low-speed image sensor and polygon mirror in an outdoor environment. In Proceedings of the 2016 Eighth International Conference on Ubiquitous and Future Networks (ICUFN), Vienna, Austria, 5-8 July 2016; pp. 51-55. [PubMed] [CrossRef]

124. Yamazato, T.; Kawagita, N.; Okada, H.; Fujii, T.; Yendo, T.; Barai, S.; Kamakura, K. The uplink visible light communication beacon system for universal traffic management. IEEE Access 2017, 5, 22282-22290. [PubMed] [CrossRef]

(C) 2019 by the authors. Licensee MDPI, Basel, Switzerland. This article is an open access article distributed under the terms and conditions of the Creative Commons Attribution (CC BY) license (http:/ / creativecommons.org/licenses/by/4.0/). 